\title{
Sexual Development in Adolescence: An Examination of Genetic and Environmental Influences
}

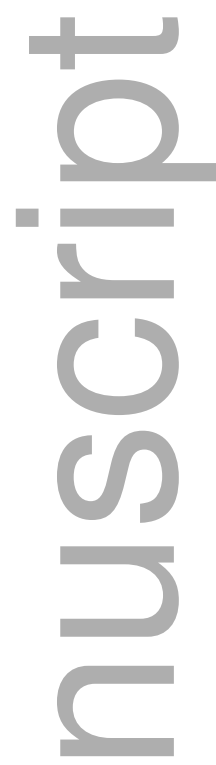

\author{
D. Angus Clark \\ University of Michigan \\ C. Emily Durbin \\ Michigan State University \\ Mary M. Heitzeg \\ University of Michigan \\ William G. Iacono \& Matt McGue \\ University of Minnesota \\ Brian M. Hicks \\ University of Michigan
}

Acknowledgement: This work was supported by United States Public Health Service grants R01 AA09367 (McGue), R01 AA024433 (Hicks), and T32 AA007477 (F. Blow) from the National Institute on Alcohol Abuse and Alcoholism, and R37 DA005147 (Iacono) and R01 DA013240 (Iacono) from the National Institute on Drug Abuse.

Correspondence: Address correspondence to D. Angus Clark, Department of Psychiatry, Addiction Center, University of Michigan, Rachel Upjohn Building, 4250 Plymouth Rd., Ann Arbor, MI 48109. Electronic mail may be sent to cladavid@med.umich.edu.

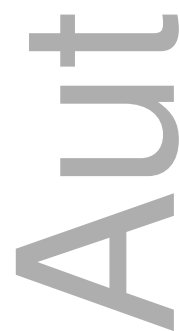

This is the author manuscript accepted for publication and has undergone full peer review but has not been through the copyediting, typesetting, pagination and proofreading process, which may lead to differences between this version and the Version of Record. Please cite this article as doi: 10.1111/JORA.12540

This article is protected by copyright. All rights reserved 


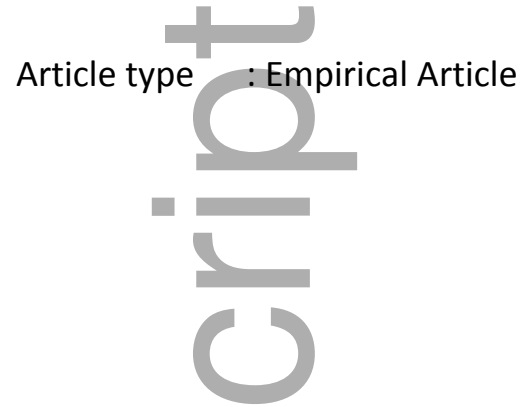

\section{Abstract}

Sexual development entails many experiences and is a major feature of adolescence. Most relevant behavioral genetic studies, however, focus primarily on sexual behaviors associated with health-risks. We took a more normative, developmental perspective by examining genetic and environmental influences on five sexual behaviors ranging from dating to pregnancy in middle $\left(\mathrm{M}_{\mathrm{age}}=14.90\right.$ years $)$ and late adolescence $\left(\mathrm{M}_{\mathrm{age}}=17.85\right.$ years $)$ in a sample of twins $(\mathrm{N}=3762)$. Overall, behaviors that are more common and socially sanctioned (e.g., dating) were more heritable than behaviors that are less common and socially acceptable (e.g., sexual intercourse). That the etiology of different sexual behaviors is tied to their normativeness highlights the importance of considering the broader developmental context when studying sexual development.

Keywords: Sexual development, Adolescence, Behavioral genetics, Heritability, Twin

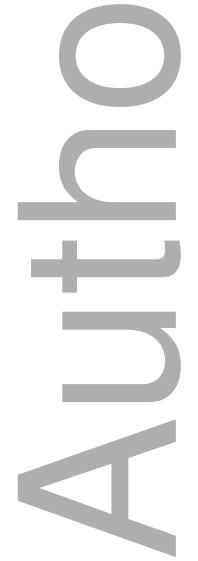




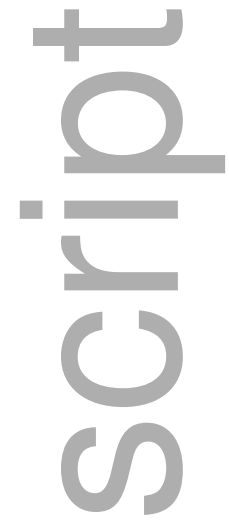

\section{Introduction}

Adolescence is a key period in the lifespan for sexual development. During adolescence reproductive maturity is reached, and sexual intercourse and intimate partner relationships are commonly initiated. Although sexual development is a natural part of adolescence, adolescent sexuality is often studied from a health-risk perspective (Harden, 2014; Moran, 2000; O'Sullivan \& Thompson, 2014; Tolman \& McClelland, 2011). Adolescent sexual development, however, entails a wide array of behaviors and experiences. Some of these are associated with greater risk, but others can promote positive adjustment (e.g., dating; Bouchey \& Furman, 2003; O'Sullivan \& Thompson, 2014). Moreover, the developmental implications of specific sexual behaviors and experiences often depends upon the context (e.g., early versus late adolescence) in which they take place (Hensel \& Fortenberry, 2014; O’Sullivan \& Thompson, 2014).

Behavioral genetic methods can be a powerful tool for understanding the broad genetic and environmental forces contributing to variability across these different dimensions of sexual development. However, behavioral genetic investigations of adolescent sexual development tend to focus on sexual intercourse and closely-related behaviors tied to health-risks (e.g., Verweiji et al., 2009; Zietsch et al., 2010). It is important to complement these narrower, risk-based investigations with those conceptualizing adolescent sexuality more broadly, as a natural developmental process (i.e., a more sex positive perspective; Harden, 2014; Tolman \& McClelland; Russel, 2005; Welsh, Rostosky, \& Kawaguchi, 2000). Indeed, different facets of sexual development may have different correlates and distinct etiological influences. Specific sexual behaviors and experiences also need to be considered within their broader developmental 
context, as the origins and consequences of different sexual behaviors will likely shift over time given the rapid biological, psychological, and social change in adolescence.

Accordingly, we examined several sexual behaviors and experiences in both middle ( age 14/15) and late ( age 17/18) adolescence at the phenotypic and genetic level using a twin sample of largely European American youth. Our first goal was to document changes over time in the rates of sexual behaviors ranging from more (e.g., dating) to less (e.g., pregnant) typical, and use these behaviors as indicators of a latent "sexual propensity" trait. We expected that all behaviors would increase in prevalence over time, and that latent variable measurement models would provide a means of formalizing the relative normativeness of different behaviors through quantitative measures such as item difficulty (i.e., the probability of engaging in a specific behavior given a person's latent sexual propensity), and tests of how these difficulties change over time. Our second goal was to investigate the genetic and environmental contributions to variability in individual behaviors and the latent sexual propensity trait to explore the possibility that etiologic trends are related to a behavior's relative normativeness. By providing an account of the interplay between normativeness and timing in the origins of sexual behaviors this study extends prior behavioral genetic work on sex in adolescence, and helps provide a conceptual bridge between sex positive and health risk perspectives on adolescent sexual development (Tolman \& McClelland, 2011).

\section{The Range of Sexual Behaviors in Adolescence}

Sexual development in adolescence entails many behaviors and experiences beyond heterosexual penile-vaginal intercourse. These experiences can be conceptualized as existing along a continuum of "normativeness", as defined by their prevalence and level of social approval in a given cultural/historical context (Barker, 1995; Tolman \& McClelland, 2011). For example, behaviors that are relatively common and have a high level social approval in contemporary U.S. society (e.g., dating and hand-holding) are more normative than those that are less common and have a lower level of social approval (e.g., vaginal and anal intercourse) (Kendall, 2014; O'Sullivan \& Thompson, 2014). This conceptualization is also consistent with data indicating that less normative sexual behaviors are associated with poorer psychosocial functioning. For example, most U.S. youth will not become pregnant or impregnate a partner (Kost, Henshaw, \& Carlin, 2010), but teen pregnancy is associated with a host of long-term negative consequences (Boden, Fergusson \& Horwood, 2008). In contrast, more normative 
behaviors such as dating and breakups (i.e., dissolution of a romantic relationship) are common and may promote positive adjustment (Carver, Joyner, \& Udry, 2003; Giordano, Manning, \& Longmore, 2010; Stone \& Ingham, 2002), or are at least only rarely associated with negative long-term consequences (Emanuele, 2008; Joyner \& Udry, 2000; Monroe, Rohde, Seeley, \& Lewinsohn, 1999). An individual sexual behavior's location on the normativeness continuum may thus have implications for broader adjustment, and can help highlight the extent to which different facets of sexual development should be viewed as a health risk behavior or not.

The location of specific sexual behaviors and experiences on this continuum of normativeness is not static though. Rather, location on the continuum is contingent on many factors such as contemporary social attitudes (e.g., the extent to which premarital sex is generally tolerated), youth identity (e.g., sexual minority versus not), and timing (e.g., early or later sexual debut) (Tolman \& McClelland, 2011). For the purposes of the present investigation, we specifically focused on timing. Indeed, sexual development is a process that unfolds across the lifespan, meaning the implications of individual sexual experiences for psychosocial functioning cannot be removed from their broader developmental context (Campbell, Mallappa, Wisniewski, \& Silovsky, 2013; Hensel \& Fotenberry, 2014; Lamb \& Plocha, 2014; Zimmer-Gembeck \& Helfand, 2008). For example, dating at age 14 is neither uncommon nor associated with much health risk for heterosexual youth (Carver, Joyner, \& Udry, 2003), but sexual intercourse at age 14 is uncommon and has strong associations with several problem behaviors such as delinquency and substance use (Armour \& Haynie, 2007; Zimmer-Gembeck \& Helfand, 2008). By age 17, however, both dating and intercourse are fairly common, and intercourse is more weakly associated with problem behaviors (Armour \& Haynie, 2007; Zimmer-Gembeck \& Helfand, 2008).

Although we have so far stressed the importance of considering specific sexual behaviors of varying normativeness, the interrelatedness of distinct behaviors is also worth exploring. For instance, sexual intercourse often occurs in the context of dating relationships (de Graff, van de Schoot, Woertman, Hawk, \& Meeus, 2012; Giordano, Manning, \& Longmore, 2010), though not all dating relationships are sexually active, and in the U.S. and similar cultures sexual experiences outside of romantic relationships (e.g., hookups, friends with benefits) are not uncommon (Lehmiller, VanderDrift, \& Kelly, 2011; Manning, Longmore, \& Giordano, 2005). Consequently, adolescent sexual behaviors can be considered both in isolation-because they 
may have distinct correlates and influences - and as indicators of a latent trait that captures individual differences in a general propensity towards romantic relationships and sexual activity. That is, some youth are more likely than others to engage in a variety of romantic and sexual behaviors, and these individual differences may provide a useful means of considering broad trends in sexual development across adolescence, and identifying youth that are most likely to engage in more versus less risky sexual activity.

The ideas of a broad sexual propensity trait and continuum of normativeness can be formalized analytically by employing statistical approaches such as those based on item response theory (IRT; de Ayala, 2009) and confirmatory factor analysis (CFA; Kamata \& Bauer, 2008). Such methods help quantify the normativeness of different sexual behaviors, demonstrate their utility as markers of a general sexual propensity trait, and provide a means to rank youth in terms of general sexual propensity. These models are also useful for directly testing developmental changes and gender differences in the normativeness of sexual behaviors (i.e., tests of differential item functioning, or DIF; Tay, Meade, \& Cao, 2015).

\section{Genetic and Environmental Influences on Sexual Behaviors across Adolescence}

Behavioral genetic methods leverage the genetic similarities between different types of related people (e.g., identical and fraternal twins) to estimate of the extent to which genetic and environmental influences account for individual differences in sexual behavior. There is evidence that both genetic and environmental differences between youth are related to individual differences in age of first intercourse (Bailey et al., 2000; Lyons et al., 2004), and that environmental forces make considerable contributions to the variability in risky sexual behaviors (Verweiji et al., 2009; Zietsch et al., 2010). Although these are important findings, existing behavioral genetic studies tend to focus on sexual intercourse and risky (i.e., less normative) sexual behaviors, and do not to investigate the changing dynamics that occur in adolescence across time (e.g., Donahue et al., 2013; Harden, Mendle, Hill, Turkheimer, \& Emery, 2008; Verweiji et al., 2009; Zietsch, Verweij, Bailey, Wright, \& Martin, 2010).

Consequently, there is a need for more research on how genetic and environmental influences vary across a wider range of sexual behaviors, and how these patterns change over the course of adolescence. For example, as sexual behaviors become more normative in later adolescence, variation may become less strongly influenced by shared environmental forces. This prediction follows from the consistent finding that shared environmental influences on 
many psychological variables decrease with age (Burt, 2009; McGue \& Gottesman, 2015; Plomin, DeFries, Knopik, \& Neiderhiser, 2016). As adolescents grow older environmental constraints on behavior are loosened so that genetically-based individual differences are better able to manifest themselves and youth can more easily self-select into preferred environments (a process often referred to as an active gene-environment correlation; Scarr \& McCartney, 1983). For example, older adolescents are able to drive and are thus more capable of seeking out situations that facilitate sexual activity, if they are so inclined (e.g., contexts without adult supervision; O'Sullivan \& Thompson, 2014). Between the general trend of greater heritability over time, and the fact that sexual behavior becomes more normative as youth age, it is reasonable to expect that sources of variation in sexual behaviors will change across adolescence in the direction of greater genetic influences.

Although the proportion of genetic versus environmental influence may change over time, sexual behaviors in early and late adolescence are not independent. Youth more likely to date at age 14 are more likely to be sexually active at age 17 . Therefore, it is also important to consider the continuity of sexual behaviors at both the phenotypic and genetic/environmental level. Even behaviors that are largely environmental across adolescence could be influenced by different contextual variables at different times. Information regarding the stable and unique etiologic influences on different facets of sexual development can thus usefully highlight which behaviors, and when, might be more amenable to interventions targeted at specific features of the environment -- if changing the prevalence of a certain behavior is desirable -- and the extent to which these contextual presses may be transient or enduring.

\section{Present Study}

The goal of the present study was to provide a more holistic account of sexual development in adolescence from a behavioral genetic perspective. This entailed both a psychometric component -- to quantify different behaviors' position on a continuum of normativeness at different times -- and a biometric component -- to examine etiologic influences on different facets of sexual development spanning a range of normativeness across adolescence. This extends the existing behavioral genetic literature on sexual development -- primarily focused on risky (i.e., less normative) sexual behaviors -- and represents one answer to calls for greater integration between sex positive and health risk perspectives on adolescent sexual development (Tolman \& McClelland, 2011). That is, each of these perspectives has merit, but 
alone they fail to capture adolescent sexual development in all its nuance; sexual behaviors are indeed a natural part of adolescence, but can also contribute to undesirable health outcomes. By framing sexual behaviors as falling on a general continuum of normativeness it is possible to simultaneously consider a wide range of behaviors and their implications, and take a multifaceted, more value-neutral (i.e., neither overemphasizing nor downplaying potential risks; Diamond, 2006; Russell, 2005; Tolman \& McClelland, 2011) approach to examining and discussing sexual development. The results presented below illustrate the utility of this conceptual approach, and lay a foundation for future investigation to build up a broader, more complete understanding of sexual development in adolescence.

We specifically examined different sexual and dating behaviors in middle and late adolescence at both a phenotypic and etiologic level using a twin sample. Youths' experiences with dating, breaking up, sexual intercourse, pregnancy scares (i.e., non-trivial worries about an unplanned pregnancy), and pregnancy were all considered. These behaviors were examined around age 14 and age 17 . Although romantic interests and dating behaviors are fairly common at age 14, youth are often still in the midst of puberty (especially boys, who develop later in this regard) and sexual intercourse at this stage is considered early (Halpern \& Haydon, 2012; Zimmer-Gembeck \& Helfand, 2008). Conversely, puberty is completed for most youth by age 17 , and sexual intercourse is more common (though not necessarily socially sanctioned in the U.S.; Kendall, 2014).

The analyses included four major components. First, we calculated rates of endorsement for the different behaviors at each time point. Second, we used IRT models to estimate the normativeness of each behavior and its utility as a marker of a general sexual propensity trait. Differences in model parameters were considered across time (i.e., DIF). Third, we estimated the genetic and environmental influences contributing to variability at each time point for both the individual behaviors and a latent sexual propensity factor. Fourth, the continuity of genetic and environmental influences across time was examined for the individual behaviors and general sexual propensity. Gender differences were considered at all stages of analysis given differences in rates of maturation, behavioral frequencies, social expectations, and subjective experiences that have been documented across adolescent girls and boys in the U.S. (CDC, 2017; O'Sullivan \& Ronis, 2013; O’Sullivan \& Thompson, 2014).

\section{Method}




\section{Participants}

The sample consisted of 3762 (52\% female) twins (1881 pairs) from the ongoing Minnesota Twin Family Study (MTFS), a longitudinal study investigating the development of psychosocial adjustment (Iacono et al., 1999). All twin pairs were the same sex, and at the time of recruitment were living with at least one biological parent, and free from any disability that would interfere with study participation. Twins were recruited the year they turned either 11years old $(n=2510)$ or 17 -years old $(n=1252)$. Twins were then invited to return for follow-up assessments every 3-5 years. Twins in the younger cohort were born from 1977 to 1984 and from 1988 to 1994 , while twins in the older cohort were born from 1972 to 1979 . Consistent with the demographics of Minnesota for the target birth years, $96 \%$ of participants reported European American ancestry. Parents were also representative of the state in terms of socioeconomic variables for the target birth years. For example, a high school diploma or equivalent was the mode for educational achievement (63.5\% for fathers, and $62.6 \%$ for mothers) while $28.5 \%$ of fathers and $25.1 \%$ of mothers earned at least a BA/BS degree. The median household income was $\$ 45,001$ to $\$ 50,000$ at the baseline assessment (1990-1996 for the majority of participants). Twenty five percent of families had an annual income of less than $\$ 40,000$ while $25 \%$ had an annual income greater than $\$ 60,001$. Seven percent of families had an annual income less than $\$ 20,000$, meeting federal poverty guidelines for a family of four in the relevant data collection years (U.S. Census Bureau, 1996). Most rearing parents $(79.3 \%)$ were married at the intake assessment, though $16.7 \%$ were divorced, $2.7 \%$ were never married and $1.3 \%$ were separated. There was also a good representation of families that resided in rural/small town (40\%) or urban (60\%) communities (Legrand, Keyes, McGue, Iacono, \& Krueger, 2008). To assess sampling bias, a brief self-report inventory was obtained from $83 \%$ of families that declined participation. Years of education were only slightly higher for participating versus non-participating parents (13.7 versus 13.4 years for mothers, and 14.0 versus 13.8 years for fathers), and there were no differences in occupational status for fathers or rates of self-reported history of or treatment for alcohol use problems or major depression for mothers and fathers (Iacono et al., 1999).

All twins were assessed at age $17\left(\mathrm{M}_{\text {age }}=17.85\right.$ years; $\mathrm{SD}=.64$ years $)$, but only the younger cohort was assessed at age $14\left(\mathrm{M}_{\text {age }}=14.90\right.$ years; $\mathrm{SD}=.31$ years $)$. Consequently, differences in sample size at the two ages do not reflect systematic attrition. Attrition was low for twins of the younger cohort: $91.4 \%$ and $86.3 \%$ were assessed at ages 14 and 17, respectively. At the age 14 
assessment, there were 395 male and 394 female monozygotic (MZ) twins, and 220 male and 246 female dizygotic (DZ) twins. At the age 17 assessment, there were 585 male and 620 female MZ twins, and 319 male and 357 female DZ twins. Zygosity was originally assessed by parents' reports on a standard zygosity questionnaire and staff evaluations of physical similarity of eyes, hair, face, ears, and fingerprint ridge counts (Iacono et al., 1999), and has since been confirmed by genome wide genotyping (McGue et al., 2013).

\section{Adolescent Sexual Behaviors}

Adolescent sexual behaviors were assessed using the Life Events Interview for Adolescents, a structured interview developed by MTFS staff to assess a variety of experiences (Billing, Hershberger, Iacono, \& McGue, 1996; Bemmels et al., 2008). We focused on five questions related to heterosexual behaviors and experiences: "Have you started dating?", "Have you and a romantic partner ever broken up?", "Have you had intercourse?", "Were you ever really afraid that you might be pregnant?" (female twins) or "Were you ever really afraid you got a girl pregnant? (male twins; not asked for males of the older cohort), and "Did you ever become pregnant?"(female twins) or "Did you get a girl pregnant?" (male twins).

\section{Data Analytic Strategy}

First, behavior endorsement frequencies were calculated across time and gender. Second, the behaviors were used as indicators of a latent factor in a 2 parameter logistic (i.e., 2PL) item response theory (IRT; de Ayala, 2009) model. In these models the sexual propensity factor was placed on a standard metric, with a mean of 0 and variance of 1 . Two major parameters of interest were estimated. The discrimination parameters are analogous to the factor loadings in a CFA, and index how strongly each behavior is related to the latent sexual propensity factor. To facilitate interpretability, discrimination values were converted into standardized factor loadings before being presented (de Ayala, 2009). The difficulty parameters denote the point along the latent continuum at which the endorsement likelihood of a given behavior is $50 \%$. Put another way, youth with factor scores above the difficulty value are more than $50 \%$ likely to endorse a given behavior. It is these difficulty parameters that can specifically provide a measure of normativeness as they indicate the location on the sexual propensity continuum where the individual behaviors fall.

The 2PL models were originally estimated individually at each time point for the full sample, and for males and females separately. Tests of DIF were then conducted to test for 
differences in the item parameters across time and gender. All discrimination and difficulty parameter estimates were constrained across time or gender, with the mean and variance of one latent factor set to 0 and 1 , respectively, for identification (the baseline model; Tay et al., 2015). We allowed the item parameters to differ across time or gender one behavior at a time, and compared the fit of this less restricted model to the baseline model. A statistically significant change in fit as indexed by the change in chi square test indicated a significant difference in the parameter estimates across time or gender. Discrimination and difficulty parameter estimates were constrained together in these procedures as this provides a more concise, holistic representation of item functioning. Further, equivalency in only one item parameter still implies a degree of measurement bias across time or groups.

Univariate ACE models were then estimated (Prescott, 2004) wherein the intraclass correlations between members of a twin pair for MZ and DZ twins were used to parse the phenotypic variance into additive genetic $\left(\mathrm{a}^{2}\right)$, common or shared environmental $\left(\mathrm{c}^{2}\right)$, and nonshared environmental $\left(\mathrm{e}^{2}\right)$ variance components. The additive genetic variance component reflects the extent to which individual differences are a function of genetic differences between people, while the shared environmental variance component reflects environmental forces that increase similarity among family members, and the non-shared environmental variance component reflects environmental forces (including non-systematic measurement error) that decrease similarity among family members. Each behavior was considered individually at each time point for both the full sample and separately by gender. Multi-group models were then used to formally test for gender differences in each behavior at both time points. Models with the three ACE components constrained to equality across gender were compared to models with ACE components freely estimated across gender. Change in model fit was then evaluated using the chi square difference test. If there was evidence that the constraints led to a statistically significant reduction in fit, ACE components were individually constrained to identify specific sources of misfit.

Common pathway models were then used to decompose the variance of the latent sexual propensity factor into the ACE variance components (see Figure 1). In this model, the variance of each behavior was parsed into ACE variance associated with the latent factor and ACE variance specific to each behavior (i.e., residual variance). Because these models can be computationally intensive, the measurement model factor loadings and thresholds were fixed to 
values derived from time and gender matched phenotypic factor models previously estimated to facilitate model convergence. Common pathway models were estimated separately at each time point for both the full sample and boys and girls specifically. Gender differences were tested using multi-group models.

Finally, bivariate Cholesky Decomposition models were fit to examine continuity in genetic and environmental influences over time (see Figure 2). These models included both a behavior at age 14 and its counterpart at age 17 . Variance in the behavior at age 14 was decomposed in a manner consistent with the univariate ACE models. The same behavior at age 17 had its variance decomposed as a function of both the ACE components on the behavior at age 14, and a set of ACE components specific to the behavior at age 17. The ACE components on the age 17 behavior from age 14 capture the extent to which genetic and environmental influences relevant at age 14 are related to individual differences at age 17 . The ACE components at age 17 capture genetic and environmental influences that are unique to variability at age 17. Bivariate models were run for the whole sample and for females and males separately. Gender differences were tested using multi-group models. All behaviors were examined except for pregnancy, due to low endorsement at age 14. A composite variable computed as the mean of the sexual behaviors was used to examine continuity in influences underlying variability in general sexual propensity. This composite score was used to reduce computational difficulties when estimating latent factor scores.

Models were estimated in Mplus version 8.1 (Muthen \& Muthen, 2018) using robust maximum likelihood estimation (MLR) for the IRT analyses, and weighted least squares mean and variance adjusted estimation (WLSMV) for the biometric analyses. Biometric models were run using the non-parametric percentile bootstrap procedure with 1000 draws, which provides reliable confidence intervals under a variety of complex data conditions (Falk, 2018).

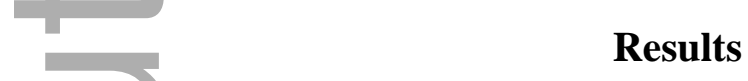

Frequencies for the different sexual behaviors across time and gender can be found in Table 1. The percentages of youth endorsing a particular behavior at a given time are presented in bold. Across time, the relative prevalence of behaviors was preserved such that behaviors more (e.g., dating) or less (e.g., sexual intercourse) common at age 14 maintained their rank ordering at age 17. Chi square goodness of fit tests indicated that all behaviors were endorsed at a significantly greater frequency at age 17 relative to age 14 ( $\chi^{2}$ values from 2021.63 to 9458.44 
with 1 degree of freedom; all ps <.01). For example, the prevalence of dating - the most frequent behavior-increased from $45 \%$ at age 14 to $83 \%$ at age 17, while the prevalence of pregnancy - the least frequent behavior - was $0.01 \%$ at age 14 and $3 \%$ at age 17 . Chi square goodness of fit tests also indicated that females were significantly more likely to report sexual intercourse at age $14\left(\chi^{2}=9.30, \mathrm{df}=1, \mathrm{p}<.01\right)$, and every behavior except breaking up at age 17 $\left(\chi^{2}\right.$ values from 15.46 to 42.57 with 1 degree of freedom; all ps <.01). In absolute terms however these differences were small.

Twins that reported sexual activity at the age 14 assessment (i.e., sexual intercourse, pregnancy scares) were somewhat more likely to be missing at the age 17 assessment (the tetrachoric correlations between these behaviors and attrition ranged from $r=.22$ to .34$)$. There were also some differences between cohorts at age 17 such that youth in the older cohort were somewhat more likely to have dated $\left(86 \%\right.$ versus $\left.82 \% ; \chi^{2}=14.68, \mathrm{df}=1, \mathrm{p}<.01\right)$, broken up $\left(69 \%\right.$ versus $\left.64 \% ; \chi^{2}=14.22, \mathrm{df}=1, \mathrm{p}<.01\right)$, and been worried about a possible pregnancy $(18 \%$ versus $\left.12 \% ; \chi^{2}=23.30, \mathrm{df}=1, \mathrm{p}<.01\right)$ than the younger cohort. Longitudinal analyses were thus run both with and without the older cohort. However, the pattern of results and conclusions did not change across these models so the results presented below are based on the models that include both the younger and older cohorts at age 17 .

\section{Sexual Propensity Factor}

Parameter estimates from the 2PL models are presented in Table 2. To facilitate interpretation, discrimination values have been converted to standardized factor loadings. All factor loadings were strong $(\lambda>.60)$, suggesting that the endorsement of specific behaviors usefully discriminate between individuals on a broad sexual propensity trait. The difficulty values were consistent with the item frequencies such that more common behaviors were less difficult or more normative than behaviors with lower frequencies. Significant declines in item

difficulty for each sexual behavior from age 14 to age 17 were detected in the DIF analyses. The correlation between the latent sexual propensity factors at age 14 and age 17 was $r=.69, \mathrm{p}<$ .001 , indicating a high-degree of rank-order stability in overall sexual behavior from middle to late adolescence (tetrachoric correlations between the individual behaviors, and tetrachoric autocorrelations, can be found in the supplemental material).

The item characteristic curves (ICCs) for the behaviors at ages 14 and 17 are presented in Figure 3, and depict the likelihood of endorsement as a function of scores on the latent sexual 
propensity trait. All behaviors were more difficult at age 14. For example, sexual intercourse is an unlikely experience for 14-year-old adolescents whose latent sexual propensity score is less than 2.5 standard deviations above the mean, but it is a much more common experience for 17 year old adolescents, where a propensity score only .50 standard deviations above the mean is associated with likely sexual intercourse. Figure 3 also illustrates the practical implications of the dating indicator's exceptionally high factor loading; at both ages, youth more than a standard deviation above the average level of sexual propensity are almost guaranteed to have started dating. Put another way, in the absence of any other information youth who have not started dating can be reliably classified as scoring lower in general sexual propensity.

The single-group 2PL results for female and male twins are also reported in Table 2. Within gender, all items evidenced DIF over time except for the afraid pregnant item for males. The correlation between the two factors was $\mathrm{r}=.75$ and .61 , both $p$ 's<.001, for females and males, respectively. Between gender, only sexual intercourse at age 14 and break ups at age 17 demonstrated DIF. Specifically, these two items were significantly less difficult for females.

\section{Univariate ACE Models}

The results for the univariate ACE models are reported in Table 3 (twin intraclass correlations can be found in the supplemental material). ACE estimates for which the confidence intervals do not contain zero are presented in bold. At both ages 14 and 17, genetic influences accounted for slightly more than $50 \%$ of the variance in dating and breaking up, with the remaining variance attributable to non-shared environmental influences. In contrast, variance in sexual intercourse, afraid pregnant, and pregnancy was largely attributable to shared environmental influences. For sexual intercourse, there was a small increase in the estimate of additive genetic variance component from age 14 to age 17 , but the $95 \%$ confidence interval for the age 17 estimate included the age 14 estimate within its range. Variance in the pregnancy items, however, was solely due to environmental influences. For afraid pregnant, variation at age 14 was mostly due to the shared environmental influences, while variance at age 17 was equally attributable to shared and non-shared environmental influences. Variance in pregnancy at age 17 was roughly equally attributable to shared and nonshared environmental influences with no additive genetic influences.

Estimates of the ACE variance components are also reported separately for males and females in Table 3. Overall there was no evidence for statistically significant differences across 
males and females in the ACE effects from the multi-group models. The only instance where this may be surprising is at age 14, when variance in sexual intercourse for female twins was mostly attributed to shared environmental influences $\left(c^{2}=0.75 ; 95 \%\right.$ CI, 0.47 to 0.89$)$ with no additive genetic influences $\left(\mathrm{a}^{2}=0.00 ; 95 \% \mathrm{CI}, 0.00\right.$ to 0.18$)$, while the variance in sexual intercourse for male twins was mostly attributed to additive genetic influences $\left(\mathrm{a}^{2}=0.94 ; 95 \% \mathrm{CI}, 0.65\right.$ to 0.99$)$ with no shared environmental influences $\left(c^{2}=0.00 ; 95 \%\right.$ CI, 0.00 to 0.63$)$. However, the high estimate for additive genetic influence in male twins was due to the fact that only 8 twin pairs were concordant for sexual intercourse at age 14, with only 1 concordant DZ pair. The low number of concordant pairs is due to the low incidence of the behavior, especially for DZ twins, which comprise only one third of the sample. Consequently, the high parameter estimate for additive genetic influence is likely of low reliability. When both genders are included in the full model, the impact of this distribution was diluted, yielding more plausible parameter estimates for shared environmental $\left(c^{2}=0.61 ; 95 \% \mathrm{CI}, 0.08\right.$ to 0.84$)$ and additive genetic influences $\left(\mathrm{a}^{2}=\right.$ $0.20 ; 95 \% \mathrm{CI}, 0.00$ to 0.75$)$. These parameter estimates were also more consistent with those at age 17, wherein for the full sample there was a modest increase in the estimate of additive genetic influences ( $\mathrm{a}^{2}=0.31 ; 95 \% \mathrm{CI}, 0.13$ to 0.52$)$ and a modest decrease in the estimate of shared environmental influences $\left(c^{2}=0.50 ; 95 \% \mathrm{CI}, 0.31\right.$ to 0.67$)$ with no significant gender differences

\section{Common Pathway Models}

The common pathway model results are presented in Table 4. Estimates for which the confidence intervals do not contain zero are presented in bold. In addition to the ACE estimates, a fourth row $-\mathrm{F}-$ is included that reflects the proportion of variance in the individual behaviors explained by the latent factor. The residual ACE components will add up to one when combined with the F row. Variance in the general sexual propensity factor at ages 14 and 17 was mostly attributed to additive genetic $\left(\mathrm{a}^{2}=0.46\right.$ and 0.54 , respectively) and shared environmental $\left(\mathrm{c}^{2}=\right.$ 0.35 and 0.25 , respectively) influences, with small contributions from non-shared environmental influences $\left(\mathrm{e}^{2}=0.19\right.$ and 0.22 , respectively). Although the shared environmental estimate was larger at age 14, this coefficient was only significant at age 17 (likely due to the larger sample size at age 17).

Estimates of the residual ACE variance components were mostly consistent with the univariate ACE estimates such that the sum of the factor ACE variance components and residual 
ACE variance components (see Table 4) tended to equal the univariate ACE parameter estimates (Table 3). The one exception was for the afraid pregnant item at age 14. Due to convergence problems (non-convergence or convergence with negative residual variances) this factor loading had to be fixed to 1.0, implying that the latent factor explained all of the variance in this behavior. The fact that there were only a small number of strongly interrelated indicators, and that the endorsement of this item was so rare, likely contributed to the instability in this part of the model. Accordingly, the implications of the common pathway model at age 14 for the afraid pregnant item should be taken cautiously. However, no such issues arose for any indicator in the age 17 model, and this factor loading did not need to be fixed to 1.0 when the model was fit separately for male and female twins. The results for the afraid pregnant indicator from these less constrained models are largely consistent with the univariate results.

Table 4 also reports parameter estimates when the model was fit separately for male and female twins. Estimates for additive genetic influences on the general sexual propensity factor were ostensibly higher in males compared to females, especially at age 14. Unfortunately, the multi-group models for testing gender differences encountered serious computational difficulties and could not be estimated; therefore, a statistical test of this difference could not be conducted. However, given our discussion of gender differences for the univariate models, gender differences for sexual propensity traits at age 14 may be superficial. Consistent with this interpretation, the pattern of ACE results was more similar across genders in the single group models at age 17. Still, there is the possibility that the etiology of general sexual propensity differs between males and females in mid-adolescence.

\section{Bivariate ACE Models}

Results from the bivariate ACE models are presented in Table 5. The left half of the table reports the overlap in the ACE variance components at ages 14 and 17, while the right half reports ACE contributions specific to the sexual behaviors at age 17. An additional row provides the percentage of total variance in a behavior explained by the age 14 or 17 ACE variance components. The sum of the 6 ACE variance components ( 3 at age 14 and 3 at age 17) will equal 1.0, and each pair of ACE variance components across time (ages 14 and 17) will sum to the univariate ACE estimates at age 17. Across behaviors, $36 \%$ to $68 \%(\mathrm{M}=48.2 \%)$ of the genetic and environmental influences underlying variability at age 17 were attributed to influences present at age 14. Most of the common influences across time were genetic or shared 
environmental. Specifically, around half of the genetic variance in dating (46\%) and break ups $(60 \%)$, and most of the genetic variance in sexual intercourse (97\%) at age 17 was accounted for by the age 14 genetic variance components. Further, $74 \%$ and $45 \%$ of the shared environmental variance in sexual intercourse and afraid pregnant at age 17, respectively, was accounted for by the age 14 shared environmental variance components. The age 14 non-shared variance components were largely unrelated to the variance in behaviors at age 17.

For the sexual propensity composite, slightly less than half of the variance was shared across ages (42\%). Specifically, $49 \%$ of the additive genetic, $100 \%$ of the shared environmental, and $3 \%$ of the non-shared environmental variance at age 17 was accounted for by the age 14 ACE variance components. Similar results were observed in the single-gender models across male and female twins, and multi-group models did not signal any significant gender differences. One caveat is that the multi-group model for the afraid pregnant variable could not be estimated. For both genders, there was evidence for continuity in environmental influences, though for female twins the continuity in non-shared environmental influences was larger, while the continuity in shared environmental influences was larger for male twins.

\section{Discussion}

We examined developmental trends in a range of sexual behaviors and experiencesdating, breaking up, sexual intercourse, pregnancy scares, and pregnancy - across adolescence using latent variable modeling and behavioral genetics methods. Notably, the normativeness of these sexual behaviors was strongly related to estimates of genetic and environmental influences. In general, sexual behaviors that were more normative (i.e., more common with higher social approval) such as dating and breaking up were more heritable than behaviors that were less normative (i.e., less common and lower social approval; Kendall, 2014; Tolman \& McClelland, 2011) such as sexual intercourse and pregnancy. Further, the more difficult or less normative behaviors exhibited large shared environmental influences. This pattern of results suggests that environmental forces may constrain genetic predispositions for certain sexual behaviors in one direction or the other, which has implications for interpreting different sexual behaviors, and broader efforts to promote positive youth development.

\section{Summary}

Individual behaviors were initially included as indicators of a latent variable measurement model to formally quantifying the idea of behavioral normativeness. Although all 
behaviors were significantly less normative at age 14, the rank ordering of behaviors was stable across time and gender. Specifically, from least to most normative, the ordering of the behaviors was: dating, breaking up, sexual intercourse, fears about being pregnant/impregnating someone, and pregnancy/impregnating someone. This ordering is consistent with existing data on behavioral frequencies and the social approval/disapproval of specific sexual behaviors (Kendall, 2014; O’Sullivan \& Thompson, 2014). This suggests that across the continuum of sexual behaviors there is a general shift such that all behaviors, even relatively extreme ones, become more normative as youth age. Importantly, although there are differences in the rates at which boys and girls mature, and differences in the rates of sexual behaviors have often been identified in the literature - females were somewhat more likely to be sexually active in the present study - the psychometric trends observed here were largely invariant across the sexes (as were the trends discussed below).

The univariate behavioral genetic models highlighted how normativeness was associated with genetic and environmental influences. Genetic differences accounted for greater variability in more normative behaviors, while shared environmental factors account for greater variability in less normative behaviors. The bivariate ACE models demonstrated that there were both stable and time-specific genetic and environmental (both shared and non-shared) influencing variability in the sex behaviors at each time point. Relatedly, the common pathway models showed a slight increase in additive genetic influences, and decrease in shared environmental influences, from age 14 to age $17(\sim 10 \%)$ on the latent sexual propensity trait (the proportion of non-shared environmental influence was largely the same across time).

Considering the phenotypic and biometric findings together — increasing normativeness in sexual behaviors from age 14 to age 17; higher normativeness being associated with greater heritability; genetic innovation and a slight increase in additive genetic influences on the latent sexual propensity trait at age 17-it seems likely that the heritability of sexual behaviors will increase over time into young adulthood, while shared environmental influences will decrease, and non-shared environmental influences will remain relatively constant (in terms of absolute variance explained). These trends are consistent with past work showing that problem behaviors in early life (Burt, 2009; McGue \& Iacono, 2005), and risky sexual behaviors specifically (Verweiji et al., 2009; Zietsch et al., 2010), are associated with greater shared environmental influences. This suggests that there are features of the environment that either constrain or 
promote less normative sexual behaviors in adolescence, which suppresses genetic influences. For example, sexual intercourse and pregnancy in adolescence are generally discouraged in contemporary U.S. society (e.g., many high schools teach abstinence-only sex education), and as such are more difficult to engage in, which constrains variability (Kendall, 2014; O'Sullivan \& Thompson, 2014). On the other hand, less normative sexual behaviors correlate with other problem behaviors, which may all be offshoots of a riskier environment through which such behaviors are promoted (Krueger et al., 2002; McGue \& Iacono, 2005). Overall, the evidence here supports an environmentally mediated "normativeness x genotype" interaction in which behavioral normativeness at a given age serves as a proxy for broader contextual forces that inhibit the genetic expression of sexual propensities.

These results therefore also suggest that there are fewer environmental constraints on more normative sexual behaviors. Unlike sexual intercourse and pregnancy, dating in adolescence is rarely viewed as a risk worth discouraging, and is even sometimes viewed as a potentially adaptive behavior that can promote positive social and emotional development (Kendall, 2014). Genetic predispositions are thus freer to manifest themselves, making individual differences in romantic coupling behaviors a more direct reflection of youths' genetically based differences. Other heritable variables such as personality and psychopathology may then be related to variability in these sexual behaviors at both a phenotypic and genetic level (Allen \& Walter, 2018; Johnson, Vernon, \& Feiler, 2008). As noted, one implication here is that as behaviors that are less normative in adolescence become more normative and less constrained in adulthood (e.g., pregnancy is less discouraged at age 30 than at age 14), individual variability will likely exhibit stronger genetic influences. This idea is consistent with evidence that problem behaviors become more heritable in adulthood (McGue \& Iacono, 2005; McGue, Iacono, \& Krueger, 2006; though of course many sexual behaviors that are considered "problem behaviors" in adolescence are not viewed that way in adulthood), past behavioral genetic investigations of sexual activity in adulthood showing stronger heritable influences (Mustanski, Viken, Kaprio, Winter, \& Rose, 2007), and the fact we found small increases in genetic influences on variation in sexual intercourse and the sexual propensity factor from age 14 to age 17.

\section{Implications}

The interplay between normativeness and heritability we identified is consistent with a bio-ecological gene-environment interaction, or the idea that strong environmental presses 
inhibit the expression of genes related to a given phenotype (Bronfenbrenner \& Ceci, 1994). That is, genetic differences among youth seemed freer to manifest for more common behaviors that are viewed as relatively benign. This suggests that variability in other sexual behaviors in adolescence that are considered relatively innocuous (e.g., kissing) may also be more heritable than variability in other sex behaviors that are considered riskier (e.g., sexual intercourse without protection for the spread of sexual transmitted disease). Indeed, the etiologies of these different adolescent sexual behaviors still need to be empirically evaluated, but the current results provide a useful framework for understanding these different facets of sexual development. Together there was evidence for two broad developmental pathways that correspond to the two dominant perspectives in the developmental literature (Tolman \& McClelland, 2011; Zimmer \& Gembeck, 2008). First, a genetically based pathway through which more normative and potentially adaptive facets of sexual development -- those facets highlighted by the more sex-positive literature -unfold across adolescence. Second, a more environmentally based pathway through which the riskier behaviors highlighted by a health risk perspective are promoted or suppressed.

A largely environmentally based pathway for risk behaviors handily implies that the sexual behaviors most often targeted for reduction are more directly impacted by contextual factors, and thus more amenable to direct intervention. For example, many youth likely have unprotected sexual intercourse not because of a dispositional propensity towards risky sex behavior, but because they are either uninformed or misinformed about the use and effectiveness of condoms (Hensel, Stupiansky, Herbenick, Dodge, \& Reece, 2011; Hoff, Greene, \& Davis, 2003). Although some youth will be predisposed towards risky sex (and other) behaviors regardless (e.g., youth high in heritable traits such as impulsivity), the results suggest that much of the variance between youth in risky sex behaviors is due to contextual factors (e.g., inadequate sexual education, a lack of resources such as condom availability, or deviant peer affiliations).

This pattern of results justifies more targeted searches for specific features of the environment that contribute to variation in non-normative sexual behaviors using a behavioral genetics framework. It is critical not only to understand the etiology of different sex behaviors, but also the correlates of those behaviors, and the pathways through which these associations emerge. For example, deviant peer affiliations are a strong predictor of risky sex behaviors, but associations between peer groups and behavior represent a blend of both genetically based selection effects, and environmentally based socialization effects (Cruz, Emery, \& Turkheimer, 
2012; Prinstein \& Giletta, 2016). This illustrates how it will not always be apparent if associations between risky sexual behaviors and an ostensible environmental risk are primarily reflections of shared genetic or environmental pathways.

The bivariate ACE models also highlight the importance of taking the developmental context into account. These models implied that although there are stable features of the environment that consistently constrain or promote these behaviors (e.g., neighborhood risk, social mores, family values), there are also many time-specific environmental factors that contribute to variability (e.g., older peer groups, whether one can drive or not, parental monitoring efforts). Uncovering the particular environmental variables that contribute to risky sexual behaviors therefore entails the collection of longitudinal data to test how long certain environmental features affect sexual behaviors and through which mechanisms.

Finally, it is worth reiterating that despite the differences in normativeness and genetic and environmental architecture, the various sexual behaviors were all strongly inter-correlated. This is consistent with the notion of a broad, latent sexual propensity trait, or that some youth are generally more likely to engage in any sexual behavior, ranging from more to less normative. Put another way, youth that engage primarily in normative sexual behaviors are still more likely than youth who do not to engage in non-normative sexual behavior. The differences observed between the distinct sexual behaviors reinforce the importance of considering sexual behaviors individually; however the notion of a general sexual propensity trait can be a useful concept for researchers when examining broad growth trends and individual differences in sexual development. As a broad-based individual difference variable this provides a concise summary of the forces underlying general sexual development, while providing a holistic representation of individuals' predilections towards sexual activity. This can be relevant for identifying at-risk youth given that high general sexual propensity scores at a given age are associated with a greater likelihood of engaging in a range of potentially problematic behaviors across time.

\section{Limitations and Future Directions}

There were several notable limitations to this study. Information on many potential sexual behaviors such as kissing, heavy petting, and oral sex were not available. Relatedly, the data predate widespread usage of internet communication technologies in romantic contexts (e.g., sexting; O'Sullivan \& Thompson, 2014). The behaviors that were included here represent a wide range of normativeness though, and while it will be useful to fill in the missing points on 
the continuum, the general pattern seen here will likely extend to other sexual behaviors (i.e., less normative behaviors being less heritable). Furthermore, although we framed the concept of normativeness as a function of both prevalence and social approval, the data and psychometric models used cannot speak directly to social approval. However, surveys of parental attitudes, policies regarding sexual education in the U.S. (e.g., abstinence only education), and policies/research aimed at reducing certain outcomes (e.g., reducing adolescent pregnancy) suggest that at least for the behaviors considered here prevalence and social approval are broadly in alignment (Kendall, 2014). Still, an important goal of future research should be to attempt to directly operationalize the concept of social approval when considering a wider range of sexual behaviors.

The fact that only two time points were included is another limitation. The time points included span middle and late adolescence though, so together capture the years during which much of the rapid development of adolescence is taking place. Relatedly, although we emphasized the importance of the developmental context in sexual development, it is also critical to consider the more specific contexts in which sexual development unfolds. For example, there are likely different implications of sexual intercourse in adolescence depending on if youth are in or out of an intimate partnership (i.e., sex with a romantic partner versus a more casual "hook up"; O’Sullivan \& Thompson, 2014).

There were also several major demographic limitations, these results being based off of a largely white, Midwestern American sample assessed several years ago. The sample lacked racial and ethnic diversity, and moreover, information on sexual orientation was not available. Accordingly, caution is warranted in generalizing these findings to racial, ethnic, and sexual minorities. Ethnic group differences are often identified in sexual development, and the experiences of people with a non-heterosexual orientation during adolescence cannot be assumed to conform to those of people with a heterosexual orientation (Kendall, 2014; O'Sullivan \& Thompson, 2014). The trends identified here may thus differ in important ways when considering non-European origin youth, or youth who do not identify as heterosexual. Second, the MTFS began almost 30 years ago (circa 1990 though data collection for the current report extended into 2012; Iacono et al., 2006). Since the initiation of this study, rates of adolescent sexual behavior have been declining (CDC, 2017), indicating that sexual behaviors may be becoming less normative in general. 
Future work should attempt to expand the scope of these findings to more diverse youth in a more contemporary setting, as it is important to determine if any differences between youth populations in the trends considered here are more quantitative or qualitative. For example, in the absolute sense non-heterosexual dating behavior among adolescents is likely less normative than heterosexual dating behavior (i.e., rarer in the population and less socially approved of across the U.S.). Despite these absolute differences, however, it may still be the case that for nonheterosexual youth the behaviors that are relatively less normative (e.g., sexual intercourse) are more environmental in origin than those that are more normative.

Future work should also broaden the general range of the current investigation to more sexual behaviors and periods of the lifespan. Examining additional sexual behaviors will fill in gaps on the normativeness continuum, which is useful for more robustly testing the association between normativeness and heritability. Including more time points would also provide a means of examining how normativeness and heritability change when there are less (or more) constraints and social prohibitions on sexual behaviors. Additional waves of assessment also facilitate examinations of the specific developmental correlates of sexual experiences in adolescence. As noted, contextual risk factors such as parental and peer relations and individuallevel variables such as personality, may mediate the associations between timing, normativeness, and heritability. The associations between specific sexual behaviors and potentially relevant variables such as those identified should be explored at both the phenotypic and genetic level across time.

\section{Conclusion}

Sexual development is a major domain of adolescent development. Most of the existing behavioral genetics literature approaches this issue from a health-risk perspective. It is also important though to complement this work with studies based on a broader developmental understanding that treats adolescent sexuality as a natural, multi-faceted part of development. The present study examined developmental trends over time in a variety of sexual behaviors at both the phenotypic and genetic level. Results showed that different developmental processes underlie more versus less normative sexual behaviors, which has implications for efforts to promote adolescent wellness, and provides a framework for forming specific future hypotheses about sexual development. 


\section{References}

Allen, M. S. \& Walter, E. E. (2018). Linking Big Five personality traits to sexuality and sexual health: A meta-analytic review. Psychological Bulletin, 144, 1081-1110.

Armor, T., \& Haynie, D. L. (2007). Adolescent sexual debut and later delinquency. Journal of Youth and Adolescence, 36, 141-152.

Bailey, J. M., Kirk, K. M., Zhu, G., Dunne, M. P., \& Martin, N. G. (2000). Do individual differences in sociosexuality represent genetic or environmentally contingent strategies? Evidence from the Australian twin registry. Journal of Personality and Social Psychology, 78(3), 537.

Barker, R. L. (1995). The social work dictionary (3rd ed.). Washington, DC: NASW.

Billig, J. P., Hershberger, S. L., Iacono, W. G., \& McGue, M. (1996). Life events and personality in late adolescence: Genetic and environmental relations. Behavior Genetics, 26(6), 543554

Boden, J. M., Fergusson, D. M., \& Horwood, L. J. (2008). Early motherhood and subsequent life outcomes. Journal of Child Psychology and Psychiatry, 49(2), 151-160.

Bouchey, H. A., \& Furman, W. (2003). Dating and romantic experiences in adolescence. In G. R. Adams \& M. D. Berzonsky (Eds.), Blackwell Handbooks of Developmental Psychology. Blackwell Handbook of Adolescence (pp. 313-329). Malden, Blackwell Publishing.

Bronfenbrenner, U., \& Ceci, S. J. (1994). Nature-nuture reconceptualized in developmental perspective: A bioecological model. Psychological review, 101(4), 568.

Burt, S. A.-(2009). Rethinking environmental contributions to child and adolescent psychopathology: A meta-analysis of shared environmental influences. Psychological Bulletin, 135(4), 608-637. doi: 10.1037/a0015702

Campbell, C., Mallappa, A., Wisniewski, A. B., \& Silovsky, J. F. (2013). Sexual behavior of prepubertal children. In Handbook of Child and Adolescent Sexuality (pp. 145-170).

Carver, K., Joyner, K., \& Udry, J. R. (2003). National estimates of adolescent romantic 
relationships. In P. Florsheim (Ed.), Adolescent Romantic Relations and Sexual Behavior: Theory, Research, and Practical Implications (pp. 23-56). Mahwah, NJ, US: Lawrence Erlbaum Associates Publishers.

Centers for Disease Control and Prevention. (2017). Youth Risk Behavior Survey Data. Available at: www.cdc.gov/yrbs. Accessed on 11/05/2018.

Cruz, J. E., Emery, R. E., \& Turkheimer, E. (2012). Peer network drinking predicts increased alcohol use from adolescence to early adulthood after controlling for genetic and shared environmental selection. Developmental Psychology, 48 (5), 1390-1402.

de Ayala, R. (2009). The Theory and Practice of Item Response Theory. New York: Guilford Press.

De Graaf, H., Van de Schoot, R., Woertman, L., Hawk, S. T., \& Meeus, W. (2012). Family cohesion and romantic and sexual initiation: A three wave longitudinal study. Journal of Youth and Adolescence, 41(5), 583-592.

Diamond, L. M. (2006). Introduction: In search of good sexual-developmental pathways for adolescent girls. New Directions for Child and Adolescent Development, 2006, $1-7$.

Donahue, K. L., Lichtenstein, P., Långström, N., \& D'onofrio, B. M. (2013). Why does early sexual intercourse predict subsequent maladjustment? Exploring potential familial confounds. Health Psychology, 32(2), 180.

Emanuele, E. (2008). Of love and death: The emerging role of romantic disruption in suicidal behavior. Suicide and Life- Threatening Behavior, 38(4), 482-482.

Falk, C. F. (2018). Are Robust Standard Errors the Best Approach for Interval Estimation With Nonnormal Data in Structural Equation Modeling? Structural Equation Modeling: A Multidisciplinary Journal, 25(2), 244-266.

Giordano, P. C., Manning, W. D., \& Longmore, M. A. (2010). Affairs of the heart: Qualities of adolescent romantic relationships and sexual behavior. Journal of Research on Adolescence, 20(4), 983-1013.

Halpern, C. T., \& Haydon, A. A. (2012). Sexual timetables for oral-genital, vaginal, and anal intercourse: Sociodemographic comparisons in a nationally representative sample of adolescents. Research and Practice, 102(6), 1221-1228.

Harden, K. P. (2014). Genetic influences on adolescent sexual behavior: Why genes matter for 
environmentally oriented researchers. Psychological Bulletin, 140(2), 434-465.

Harden, K. P., Mendle, J., Hill, J. E., Turkheimer, E., \& Emery, R. E. (2008). Rethinking timing of first sex and delinquency. Journal of Youth and Adolescence, 37, 373-385.

Hensel, D. J., Stupiansky, N. W., Herbenick, D., Dodge, B., \& Reece, M. (2011). When condom use is not condom use: An event- level analysis of condom use behaviors during vaginal intercourse. The journal of sexual medicine, 8(1), 28-34.

Hensel, D. J., \& Fortenberry, J. D. (2014). Life-span sexuality through a sexual health perspective. APA Handbook of Sexuality and Psychology, 1, 385-413.

Hoff, T., Greene, L., \& Davis, J. (2003). National Survey of Adolescents and Young Adults: Sexual Health Knowledge Attitudes and Experiences.

Iacono, W. G., Carlson, S.R., Taylor, J., Elkins, I. J., \& McGue, M. (1999). Behavioral disinhibition and the development of substance use disorders: Findings from the Minnesota twin family study. Development and Psychopathology, 11, 869-900.

Iacono, W. G., McGue, M., \& Krueger, R. F. (2006). Minnesota center for twin and family research. Twin Research and Human Genetics, 9(6), 978-984.

Johnson, A. M., Vernon, P. A., \& Feiler, A. R. (2008). Behavioral genetic studies of personality: An introduction and review of the results of 50+ years of research. The SAGE handbook of personality theory and assessment, 1, 145-173.

Joyner, K., \& Udry, J. R. (2000). You don't bring me anything but down: Adolescent romance and depression. Journal of Health and Social Behavior, 369-391.

Kamata, A., \& Bauer, D. J. (2008). A note on the relation between factor analytic and item response theory models. Structural Equation Modeling: A Multidisciplinary Journal, 15(1), 136-153.

Kendall, N. (2014). Sexuality education. APA Handbook of Sexuality and Psychology, 2, 339-371.

Krueger, R. F., Hicks, B. M., Patrick, C. J., Carlson, S. R., Iacono, W. G., \& McGue, M. (2002). Etiologic connections among substance dependence, antisocial behavior and personality: Modeling the externalizing spectrum. Journal of Abnormal Psychology, 111(3), 411.

Kost, K., Henshaw, S., \& Carlin, L. (2010). US teenage pregnancies, births and abortions: National and state trends and trends by race and ethnicity. Guttmacher Institute. Lamb, S., \& Plocha, A. (2014). Sexuality in childhood. APA Handbook of Sexuality and 
Psychology, 1, 415-432.

Lehmiller, J. J., VanderDrift, L. E., \& Kelly, J. R. (2011). Sex differences in approaching friends with benefits relationships. Journal of Sex Research, 48(2-3), 275-284.

Lyons, M. J., Koenen, K. C., Buchting, F., Meyer, J. M., Eaves, L., Toomey, R., ... \& Jerskey, B. A. (2004). A twin study of sexual behavior in men. Archives of Sexual Behavior, 33(2), $129-136$.

Manning, W. D., Longmore, M. A., \& Giordano, P. C. (2005). Adolescents' involvement in nonromantic sexual activity. Social Science Research, 34(2), 384-407.

McGue, M., \& Gottesman, I. I. (2015). Classical and molecular genetic research on general cognitive ability. Hastings Center Report, 45(S1), S25-S31.

McGue, M., \& Iacono, W. G. (2005). The association of early adolescent problem behavior with adult psychopathology. American Journal of Psychiatry, 162(6), 1118-1124.

McGue, M., Iacono, W. G., \& Krueger, R. (2006). The association of early adolescent problem behavior and adult psychopathology: A multivariate behavioral genetic perspective. Behavior Genetics, 36(4), 591-602.

McGue, M., Zhang, Y., Miller, M. B., Basu, S., Vrieze, S., Hicks, B., . . Iacono, W. G. (2013). A genome-wide association study of behavioral disinhibition. Behavior Genetics, 43, $363-373$.

Miller, B. C., Bayley, B. K., Christensen, M., Leavitt, S. C., \& Coyl, D. D. (2006). Adolescent pregnancy and childbearing. Blackwell Handbook of Adolescence, 415-449.

Monroe, S. M., Rohde, P., Seeley, J. R., \& Lewinsohn, P. M. (1999). Life events and depression in adolescence: Relationship loss as a prospective risk factor for first onset of major depressive disorder. Journal of Abnormal Psychology, 108(4), 606.

Mustanski, B., Viken, R. J., Kaprio, J., Winter, T., \& Rose, R. J. (2007). Sexual behavior in young adulthood: A population-based twin study. Health Psychology, 26(5), 610.

Muthen, L. K., \& Muthen, B. O. (1998-2018). Mplus User's Guide. Eighth Edition. Los Angeles, CA: Muthen \& Muthen.

O’Sullivan, L. F., \& Ronis, S. T. (2013). Sexual development in girls: "Normative" development and development of paraphilias and sexual offending behaviors. In Handbook of Child and Adolescent Sexuality (pp. 193-219).

O’Sullivan, L. F., \& Thompson, A. E. (2014). Sexuality in adolescence. APA Handbook of 
Sexuality and Psychology, 1, 433-486.

Prescott, C. A. (2004). Using the Mplus computer program to estimate models for continuous and categorical data from Twins. Behavior Genetics, 34(1), 17-40.

Plomin, R., DeFries, J. C., Knopik, V. S., \& Neiderhiser, J. M. (2016). Top 10 replicated findings from behavioral genetics. Perspectives on psychological science, 11(1), 3-23.

Prinstein M. J. \& Giletta, M. (2016). Peer relations and developmental psychopathology. In D. Cicchetti,(Ed.), Developmental Psychopathology, Third Edition (Volume 1, pp. 527579). Hoboken, NJ: Wiley.

Russell, S. T. (2005). Conceptualizing positive adolescent sexuality development. Sexuality Research and Social Policy, 2(3), 4.

Scarr, S., \& McCartney, K. (1983). How people make their own environments: A theory of genotype $\rightarrow$ environment effects. Child development, 424-435.

Stone, N., \& Ingham, R. (2002). Factors affecting British teenagers' contraceptive use at first intercourse: The importance of partner communication. Perspectives on Sexual and Reproductive Health, 191-197.

Tay, L., Meade, A. W., \& Cao, M. (2015). An overview and practical guide to IRT measurement equivalence analysis. Organizational Research Methods, 18(1), 3-46.

Tolman, D. L., \& McClelland, S. I. (2011). Normative sexuality development in adolescence: A decade in review, 2000-2009. Journal of Research on Adolescence, 21(1), 242-255.

Verweij, K. J. H., Zietsch, B. P., Bailey, J. M., \& Martin, N. G. (2009). Shared aetiology of risky sexual behaviour and adolescent misconduct: Genetic and environmental influences. Genes, Brain and Behavior, 8(1), 107-113.

Zietsch, B. P., Verweij, K. J. H., Bailey, J. M., Wright, M. J., \& Martin, N. G. (2010). Genetic and environmental influences on risky sexual behaviour and its relationship with personality. Behavior Genetics, 40(1), 12.

Zimmer-Gembeck, M. J., \& Helfand, M. (2008). Ten years of longitudinal research on U.S. adolescent sexual behavior: Developmental correlates of sexual intercourse, and the importance of age, gender and ethnic background. Developmental Review, 28, 153-224. 
Table 1

Sex Behavior Frequencies Across Age and Gender

\begin{tabular}{|c|c|c|c|c|c|c|c|c|c|c|}
\hline \multirow{2}{*}{ 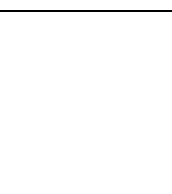 } & \multirow{2}{*}{$(1)$} & \multicolumn{3}{|c|}{ Age 14 } & \multirow[b]{2}{*}{ Pregnant } & \multirow[b]{2}{*}{ Dating } & \multicolumn{3}{|c|}{ Age 17} & \multirow[b]{2}{*}{ Pregnan } \\
\hline & & Break Up & $\begin{array}{c}\text { Sexual } \\
\text { Intercourse }\end{array}$ & $\begin{array}{c}\text { Afraid } \\
\text { Pregnant }\end{array}$ & & & Break Up & $\begin{array}{c}\text { Sexual } \\
\text { Intercourse }\end{array}$ & $\begin{array}{c}\text { Afraid } \\
\text { Pregnant }\end{array}$ & \\
\hline \multicolumn{11}{|c|}{ Full Sample } \\
\hline No & 290 & 1733 & 2227 & 2301 & 2323 & 570 & 1156 & 2140 & 2465 & 3311 \\
\hline$(\%)$ & $(55 \%)$ & $(76 \%)$ & $(96 \%)$ & $(99 \%)$ & $(99.9 \%)$ & $(17 \%)$ & $(34 \%)$ & $(63 \%)$ & $(87 \%)$ & $(97 \%)$ \\
\hline Yes & & 556 & 95 & 24 & 2 & 2842 & 2254 & 1244 & 373 & 94 \\
\hline$(\%)$ & $(45 \%)$ & $(24 \%)$ & $(4 \%)$ & $(1 \%)$ & $(.01 \%)$ & $(83 \%)$ & $(66 \%)$ & $(37 \%)$ & $(13 \%)$ & $(3 \%)$ \\
\hline \multicolumn{11}{|l|}{ Female } \\
\hline No & 657 & 891 & 1135 & 1180 & 1195 & 271 & 606 & 1086 & 1509 & 1720 \\
\hline$(\%)$ & $(55 \%)$ & $(76 \%)$ & $(95 \%)$ & $(99 \%)$ & $(99.8 \%)$ & $(15 \%)$ & $(34 \%)$ & $(61 \%)$ & $(84 \%)$ & $(96 \%)$ \\
\hline Yes & & 284 & 61 & 17 & 2 & 1524 & 1188 & 701 & 283 & 71 \\
\hline$(\%)$ & 5\%) & $(24 \%)$ & $(5 \%)$ & $(1 \%)$ & $(.02 \%)$ & $(85 \%)$ & $(66 \%)$ & $(39 \%)$ & $(16 \%)$ & $(4 \%)$ \\
\hline \multicolumn{11}{|l|}{ Male } \\
\hline No & 633 & 842 & 1092 & 1121 & 1128 & 299 & 550 & 1054 & 956 & 1591 \\
\hline$(\%)$ & $(56 \%)$ & $(76 \%)$ & $(97 \%)$ & $(99.4 \%)$ & $(100 \%)$ & $(19 \%)$ & $(34 \%)$ & $(66 \%)$ & $(91 \%)$ & $(99 \%)$ \\
\hline Yes & & 272 & 34 & 7 & 0 & 1318 & 1066 & 543 & 90 & 23 \\
\hline$(\%)$ & $4 \%)$ & $(24 \%)$ & $(3 \%)$ & $(.06 \%)$ & $(0 \%)$ & $(82 \%)$ & $(66 \%)$ & $(34 \%)$ & $(9 \%)$ & $(1 \%)$ \\
\hline
\end{tabular}

Note. Endorsement percentages bolded. 
Table 2

2PL Model Results Across Age and Gender

\begin{tabular}{|c|c|c|c|c|c|c|c|c|c|}
\hline \multirow{2}{*}{ 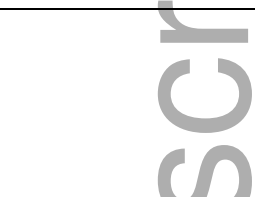 } & \multicolumn{4}{|c|}{ Age 14 } & \multicolumn{5}{|c|}{ Age 17} \\
\hline & Dating & Break Up & $\begin{array}{c}\text { Sexual } \\
\text { Intercourse }\end{array}$ & $\begin{array}{c}\text { Afraid } \\
\text { Pregnant }\end{array}$ & Dating & Break Up & $\begin{array}{c}\text { Sexual } \\
\text { Intercourse }\end{array}$ & $\begin{array}{c}\text { Afraid } \\
\text { Pregnant }\end{array}$ & Pregnant \\
\hline \multicolumn{10}{|l|}{ Full Sample } \\
\hline$\lambda$ & $1.00^{\mathrm{x}}$ & $.97^{\mathrm{x}}$ & $.67^{x}$ & $.85^{\mathrm{x}}$ & $1.00^{\mathrm{y}}$ & $.79^{\mathrm{y}}$ & $.87^{\mathrm{y}}$ & $.98^{\mathrm{y}}$ & $.86^{\mathrm{y}}$ \\
\hline $\mathrm{b}$ & $.19^{\mathrm{x}}$ & $.69^{x}$ & $2.68^{x}$ & $2.80^{x}$ & $-.98^{\mathrm{y}}$ & $-.50^{\mathrm{y}}$ & $.41^{\mathrm{y}}$ & $1.15^{\mathrm{y}}$ & $2.25^{\mathrm{y}}$ \\
\hline \multicolumn{10}{|l|}{ Female } \\
\hline$\lambda$ & $1.00^{\mathrm{x}}$ & $.96^{\mathrm{x}}$ & $.68^{x}$ & $.85^{\mathrm{x}}$ & $1.00^{\mathrm{y}}$ & $.73^{y}$ & $.91^{\mathrm{y}}$ & $.99^{\mathrm{y}}$ & $.86^{\mathrm{y}}$ \\
\hline $\mathrm{b}$ & $.10^{x}$ & $.72^{x}$ & $2.45^{x}$ & $2.63^{x}$ & $-1.02^{\mathrm{y}}$ & $-.57^{\mathrm{y}}$ & $.31^{\mathrm{y}}$ & $1.00^{\mathrm{y}}$ & $2.05^{\mathrm{y}}$ \\
\hline \multicolumn{10}{|l|}{ Male } \\
\hline$\lambda$ & $1.00^{\mathrm{x}}$ & $.98^{\mathrm{x}}$ & $.67^{x}$ & $.88^{x}$ & $1.00^{\mathrm{y}}$ & $.91^{\mathrm{y}}$ & $.76^{\mathrm{y}}$ & $.86^{\mathrm{x}}$ & $.82^{\mathrm{y}}$ \\
\hline $\mathrm{b}$ & $.21^{\mathrm{x}}$ & $.69^{x}$ & $2.90^{x}$ & $2.94^{x}$ & $-.91^{\mathrm{y}}$ & $-.44^{y}$ & $.55^{\mathrm{y}}$ & $1.59^{x}$ & $2.74^{\mathrm{y}}$ \\
\hline
\end{tabular}

Note. $\lambda=$ item factor loading; $b=$ item difficulty. Factor loadings converted from discrimination vales. Parameter estimates come from singlegroup, single-age models. Item difficulty values are on a z-score metric. Shared super-scripts denote equivalent item functioning (i.e, equal discrimination and difficulty estimates) across age. Parameter estimates in bold were unequal across females and males in tests differential item functioning.

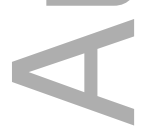

This article is protected by copyright. All rights reserved 
Table 3

Univariate ACE Model Results Across Age and Gender

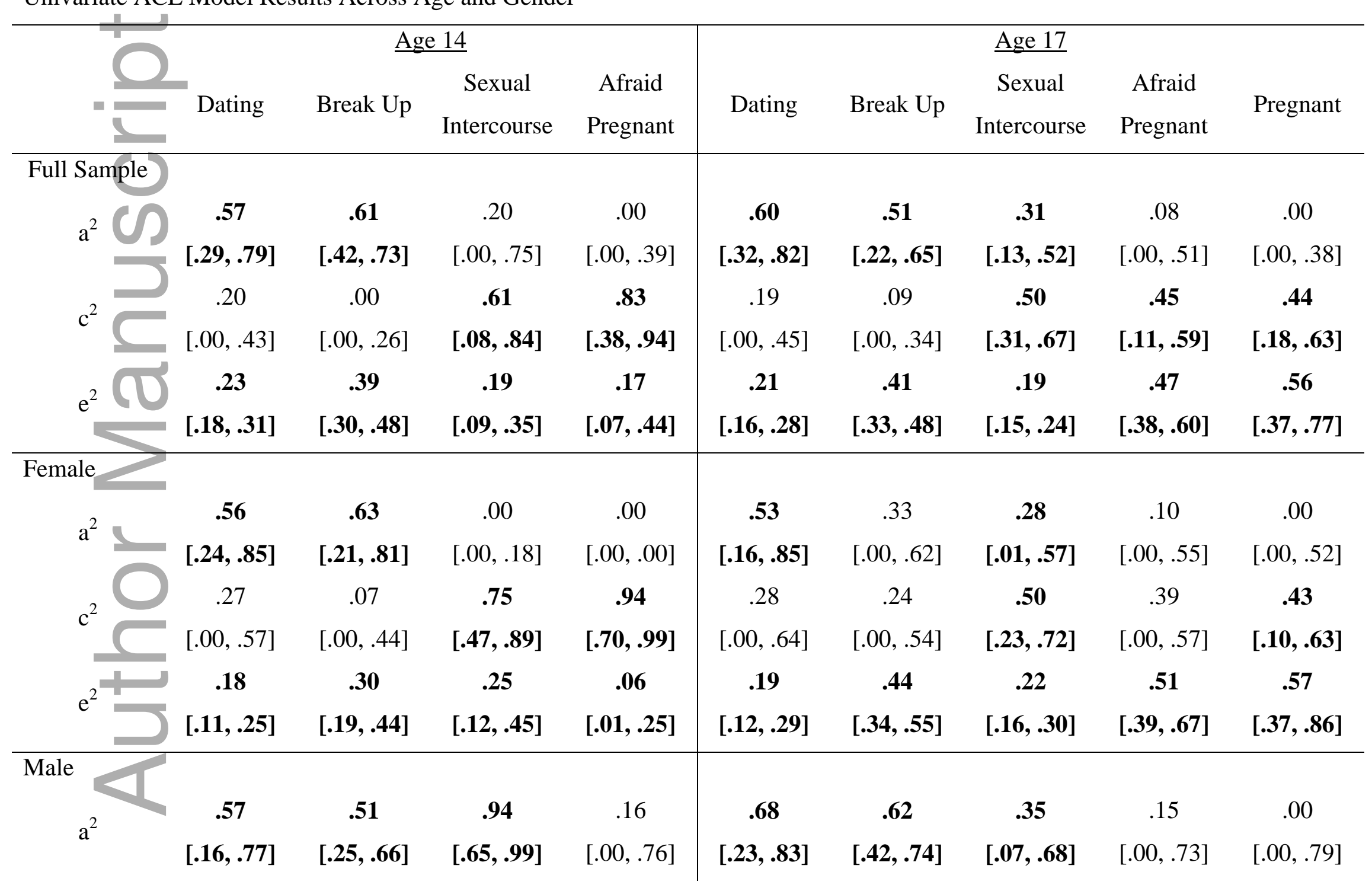




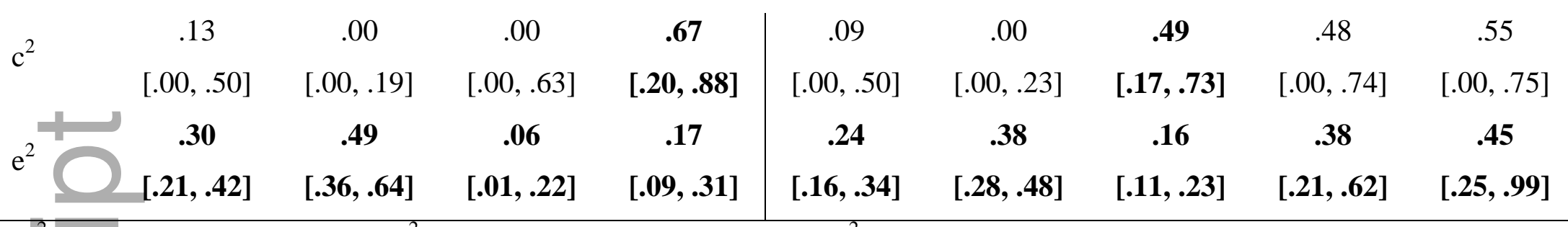

Note. $\mathrm{a}^{2}=$ additive genetic variance; $\mathrm{c}^{2}=$ shared environmental variance; $\mathrm{e}^{2}=$ non-shared environmental variance; $95 \%$ Estimates with confidence intervals that do not include zero are bolded. Parameter estimates for females and males come from single-group models. None of the variance components differed significantly across females and males when tested in multi-group models.

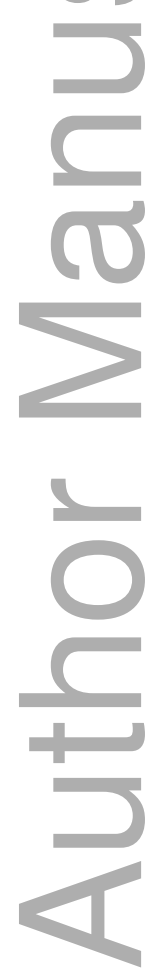


Table 4

Common Pathway Model Results

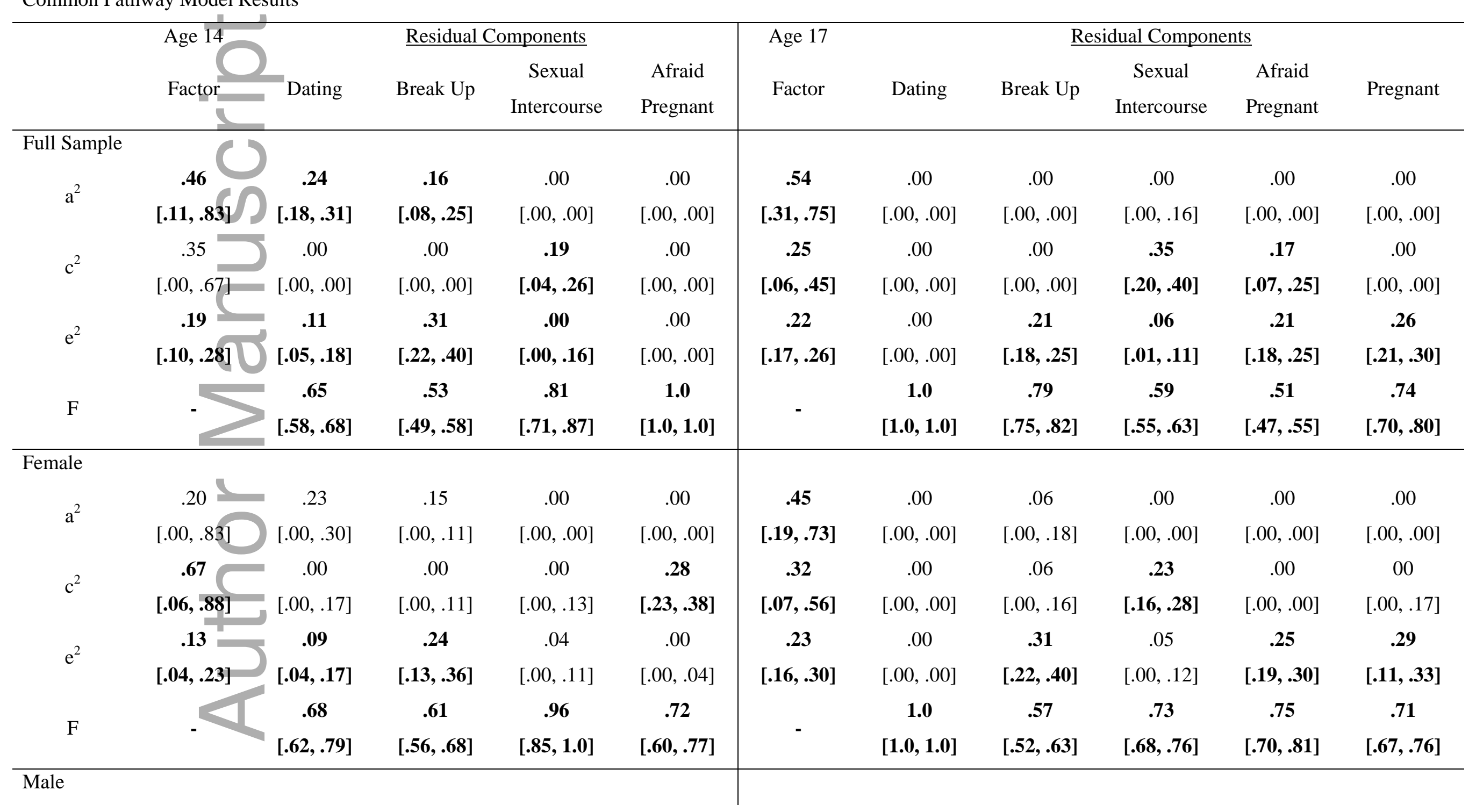




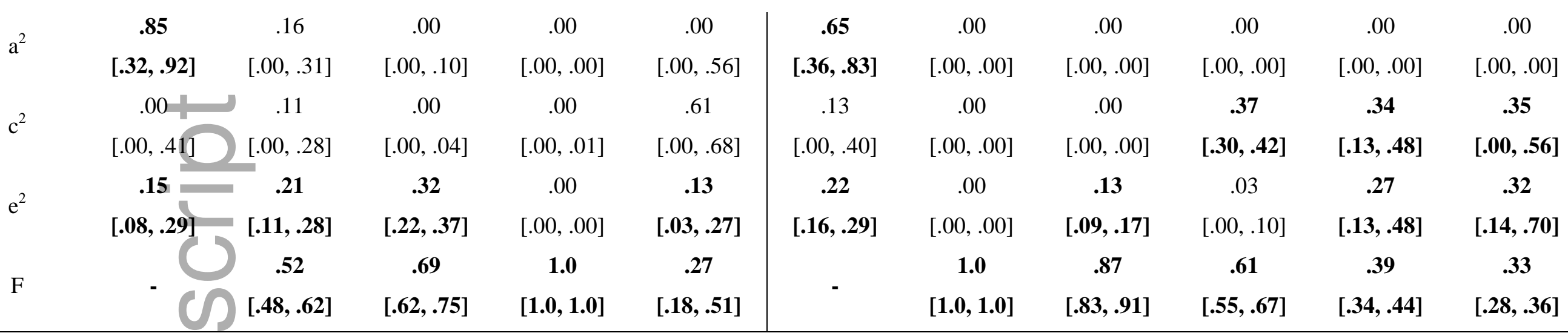

Note. $\mathrm{a}^{2}=$ additive genetic variance; $\mathrm{c}^{2}=$ shared environmental variance; $\mathrm{e}^{2}=$ non-shared environmental variance; $\mathrm{F}=$ proportion of variance explained by latent factor; $\mathrm{R}=$ residual ACE variance components. Residual ACE variance components will not sum to 1 without F because of each behaviors' relation with the latent factor. Estimates with confidence intervals that do not include zero are bolded. Parameter estimates for females and males come from single-group models.

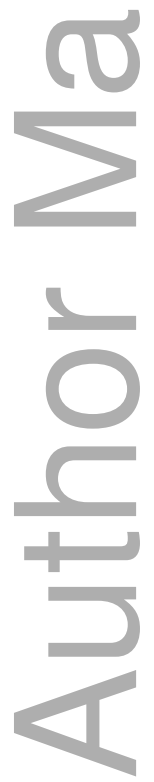


Table 5

Bivariate ACE Model Results

\begin{tabular}{|c|c|c|c|c|c|c|c|c|c|c|}
\hline & \multicolumn{5}{|c|}{$\underline{\text { Age } 14 \rightarrow \text { Age } 17}$} & \multicolumn{5}{|c|}{ Age 17 Residual } \\
\hline & Dating & Break Up & $\begin{array}{c}\text { Sexual } \\
\text { Intercourse }\end{array}$ & $\begin{array}{c}\text { Afraid } \\
\text { Pregnant }\end{array}$ & $\begin{array}{c}\text { Sexual } \\
\text { Propensity }\end{array}$ & Dating & Break Up & $\begin{array}{c}\text { Sexual } \\
\text { Intercourse }\end{array}$ & $\begin{array}{c}\text { Afraid } \\
\text { Pregnant }\end{array}$ & $\begin{array}{c}\text { Sexual } \\
\text { Propensity }\end{array}$ \\
\hline \multicolumn{11}{|l|}{ Full Sample } \\
\hline$a^{2}$ & 0.28 & $\begin{array}{c}.30 \\
{[.12, .57]}\end{array}$ & $\begin{array}{c}.31 \\
{[.03, .50]}\end{array}$ & $\begin{array}{c}.11 \\
{[.00, .40]}\end{array}$ & $\begin{array}{c}.20 \\
{[.11, .34]}\end{array}$ & $\begin{array}{c}.31 \\
{[.00, .39]}\end{array}$ & $\begin{array}{c}.20 \\
{[.00, .36]}\end{array}$ & $\begin{array}{c}.01 \\
{[.00, .24]}\end{array}$ & $\begin{array}{c}.00 \\
{[.00, .16]}\end{array}$ & $\begin{array}{c}.23 \\
{[.08, .32]}\end{array}$ \\
\hline$c^{2}$ & & .00 & .37 & .20 & .21 & .00 & .09 & .13 & .23 & .00 \\
\hline & {$[.00, .44]$} & {$[.00, .27]$} & {$[.19, .63]$} & {$[.05, .49]$} & {$[.05, .34]$} & {$[.00, .22]$} & {$[.00, .23]$} & {$[.00, .26]$} & {$[.00, .45]$} & {$[.00, .14]$} \\
\hline$e^{2}$ & .04 & .06 & .00 & .12 & .01 & .17 & .34 & .19 & .34 & .35 \\
\hline $\mathrm{e}$ & {$[.00, .12]$} & {$[.01, .15]$} & {$[.00, .04]$} & {$[.00, .50]$} & {$[.00, .02]$} & {$[.10, .24]$} & {$[.25, .43]$} & {$[.13, .23]$} & {$[.00, .53]$} & {$[.32, .39]$} \\
\hline $\begin{array}{l}\% \text { of Total } \\
\text { Variance }\end{array}$ & 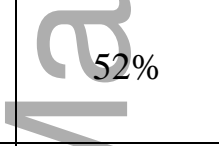 & $36 \%$ & $68 \%$ & $43 \%$ & $42 \%$ & $48 \%$ & $64 \%$ & $32 \%$ & $57 \%$ & $68 \%$ \\
\hline \multicolumn{11}{|l|}{ Female } \\
\hline$a^{2}$ & $\begin{array}{c}.14 \\
{[.01, .59]}\end{array}$ & $\begin{array}{c}.37 \\
{[.05, .57]}\end{array}$ & $\begin{array}{c}.29 \\
{[.01, .54]}\end{array}$ & $\begin{array}{c}.01 \\
{[.00, .43]}\end{array}$ & $\begin{array}{c}.20 \\
{[.08, .41]}\end{array}$ & $\begin{array}{c}.35 \\
{[.00, .45]}\end{array}$ & $\begin{array}{c}.00 \\
{[.00, .27]}\end{array}$ & $\begin{array}{c}.00 \\
{[.00, .15]}\end{array}$ & $\begin{array}{c}.04 \\
{[.00, .38]}\end{array}$ & $\begin{array}{c}.21 \\
{[.00, .34]}\end{array}$ \\
\hline$c^{2}$ & $1, .67]$ & $\begin{array}{c}.13 \\
{[.00, .40]}\end{array}$ & $\begin{array}{c}.44 \\
{[.13, .63]}\end{array}$ & $\begin{array}{c}.09 \\
{[.03, .30]}\end{array}$ & $\begin{array}{c}.22 \\
{[.01, .39]}\end{array}$ & $\begin{array}{c}.00 \\
{[.00, .28]}\end{array}$ & $\begin{array}{c}.08 \\
{[.00, .32]}\end{array}$ & $\begin{array}{c}.06 \\
{[.00, .32]}\end{array}$ & $\begin{array}{c}.33 \\
{[.00, .46]}\end{array}$ & $\begin{array}{c}.00 \\
{[.00, .23]}\end{array}$ \\
\hline$e^{2}$ & $\begin{array}{c}.18 \\
{[.04, .27]}\end{array}$ & $\begin{array}{c}.08 \\
{[.01, .26]}\end{array}$ & $\begin{array}{c}.00 \\
{[.00, .08]}\end{array}$ & $\begin{array}{c}.53 \\
{[.01, .65]}\end{array}$ & $\begin{array}{c}.01 \\
{[.00, .03]}\end{array}$ & $\begin{array}{c}.01 \\
{[.00, .16]}\end{array}$ & $\begin{array}{c}.35 \\
{[.18, .45]}\end{array}$ & $\begin{array}{c}.22 \\
{[.11, .28]}\end{array}$ & $\begin{array}{c}.00 \\
{[.00, .50]}\end{array}$ & $\begin{array}{c}.36 \\
{[.31, .40]}\end{array}$ \\
\hline $\begin{array}{l}\% \text { of Total } \\
\text { Variance }\end{array}$ & $64 \%$ & $57 \%$ & $72 \%$ & $63 \%$ & $43 \%$ & $36 \%$ & $43 \%$ & $28 \%$ & $37 \%$ & $67 \%$ \\
\hline Male & & & & & & & & & & \\
\hline
\end{tabular}




\begin{tabular}{|c|c|c|c|c|c|c|c|c|c|c|}
\hline$a^{2}$ & $\begin{array}{c}.58 \\
{[.19, .79]}\end{array}$ & $\begin{array}{c}.38 \\
{[.11, .63]}\end{array}$ & $\begin{array}{c}.17 \\
{[.00, .54]}\end{array}$ & $\begin{array}{c}.30 \\
{[.00, .49]}\end{array}$ & $\begin{array}{c}.21 \\
{[.08, .39]}\end{array}$ & $\begin{array}{c}.10 \\
{[.00, .30]}\end{array}$ & $\begin{array}{c}.25 \\
{[.00, .39]}\end{array}$ & $\begin{array}{c}.18 \\
{[.00, .44]}\end{array}$ & $\begin{array}{c}.00 \\
{[.00, .46]}\end{array}$ & $\begin{array}{c}.23 \\
{[.01, .34]}\end{array}$ \\
\hline$c^{2}$ & $\begin{array}{c}.02 \\
{[.00, .45]}\end{array}$ & $\begin{array}{c}.00 \\
{[.00, .30]}\end{array}$ & $\begin{array}{c}.50 \\
{[.07, .72]}\end{array}$ & $\begin{array}{c}.38 \\
{[.01, .55]}\end{array}$ & $\begin{array}{c}.21 \\
{[.03, .40]}\end{array}$ & $\begin{array}{c}.07 \\
{[.00, .21]}\end{array}$ & $\begin{array}{c}.00 \\
{[.00, .10]}\end{array}$ & $\begin{array}{c}.00 \\
{[.00, .40]}\end{array}$ & $\begin{array}{c}.00 \\
{[.00, .48]}\end{array}$ & $\begin{array}{c}.00 \\
{[.00, .12]}\end{array}$ \\
\hline$e^{2}$ & $\begin{array}{c}.01 \\
{[.00, .06]}\end{array}$ & $\begin{array}{c}.05 \\
{[.01, .17]}\end{array}$ & $\begin{array}{c}.01 \\
{[.00, .15]}\end{array}$ & $\begin{array}{c}.03 \\
{[.00, .40]}\end{array}$ & $\begin{array}{c}.01 \\
{[.00, .02]}\end{array}$ & $\begin{array}{c}.23 \\
{[.14, .32]}\end{array}$ & $\begin{array}{c}.33 \\
{[.19, .43]}\end{array}$ & $\begin{array}{c}.15 \\
{[.00, .22]}\end{array}$ & $\begin{array}{c}.30 \\
{[.00, .51]}\end{array}$ & $\begin{array}{c}.35 \\
{[.30, .40]}\end{array}$ \\
\hline $\begin{array}{l}\% \text { of Total } \\
\text { Variance }\end{array}$ & & $43 \%$ & $68 \%$ & $70 \%$ & $43 \%$ & $40 \%$ & $58 \%$ & $32 \%$ & $30 \%$ & $67 \%$ \\
\hline
\end{tabular}

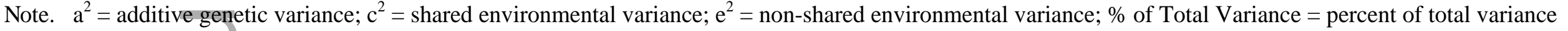
in age 17 behaviors explained by age 14 or age 17 ACE components; Age $14 \rightarrow$ Age $17=$ proportions of variance in age 17 behaviors explained by age 14 ACE components; Age 17 Residual = proportions of variance in age 17 behaviors not explained by age $14 \mathrm{ACE}$ components. Estimates with confidence intervals that do not include zero are bolded. No variance components differed significantly across females and males when tested in multi-group models.

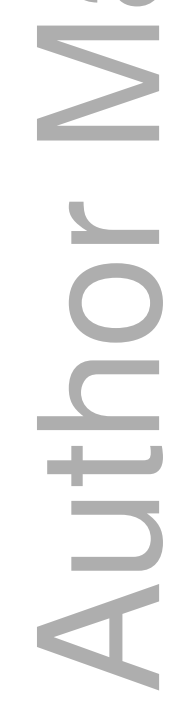

This article is protected by copyright. All rights reserved 


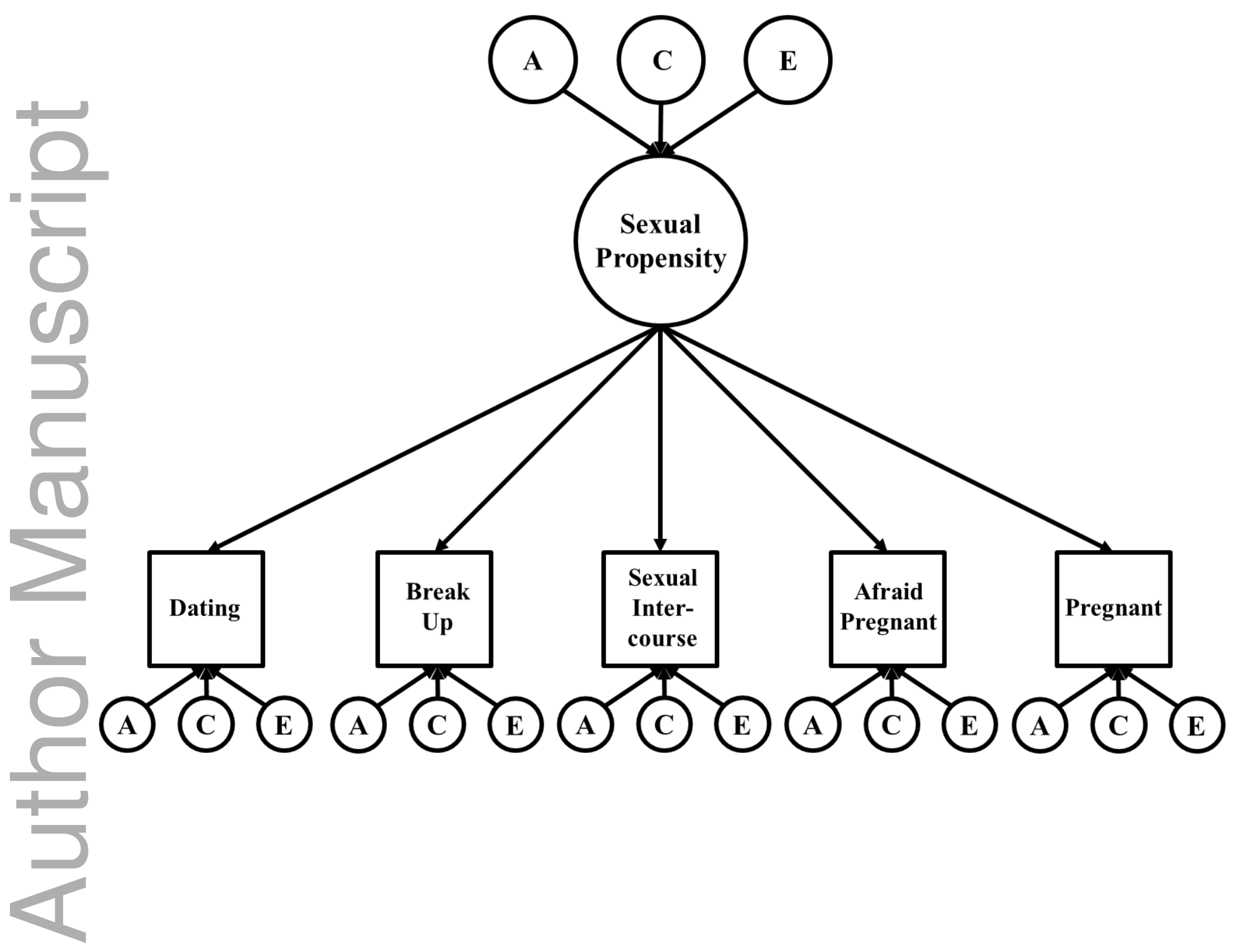


Figure 1. Common Pathway Model. A = additive genetic variance; $\mathrm{C}=$ shared environmental variance; $\mathrm{E}=$ non-shared environmental variance. Twin 2 model not pictured. Two equivalent models were specified, one for twin 1 and one for twin 2 , and covariances were added between the twin 1 and $2 \mathrm{~A}$ and $\mathrm{C}$ variance components. The covariance between the A components was fixed to either 1.0 (MZ twins) or 0.5 (DZ twins), and the covariance between the $\mathrm{C}$ components was fixed to 1.0 (MZ and DZ twins). ACE components on the sexual propensity factor capture genetic and environmental influences on the general factor. The ACE components on the individual behaviors capture genetic and environmental influences on the behavior-specific residual variances, that is, the variance that remains after accounting for the general factor.

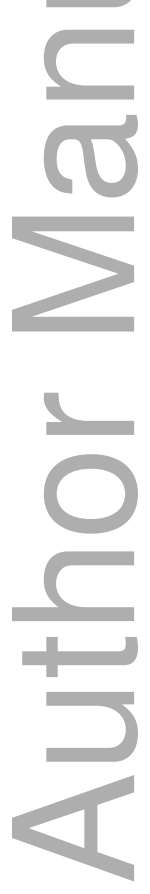

This article is protected by copyright. All rights reserved 


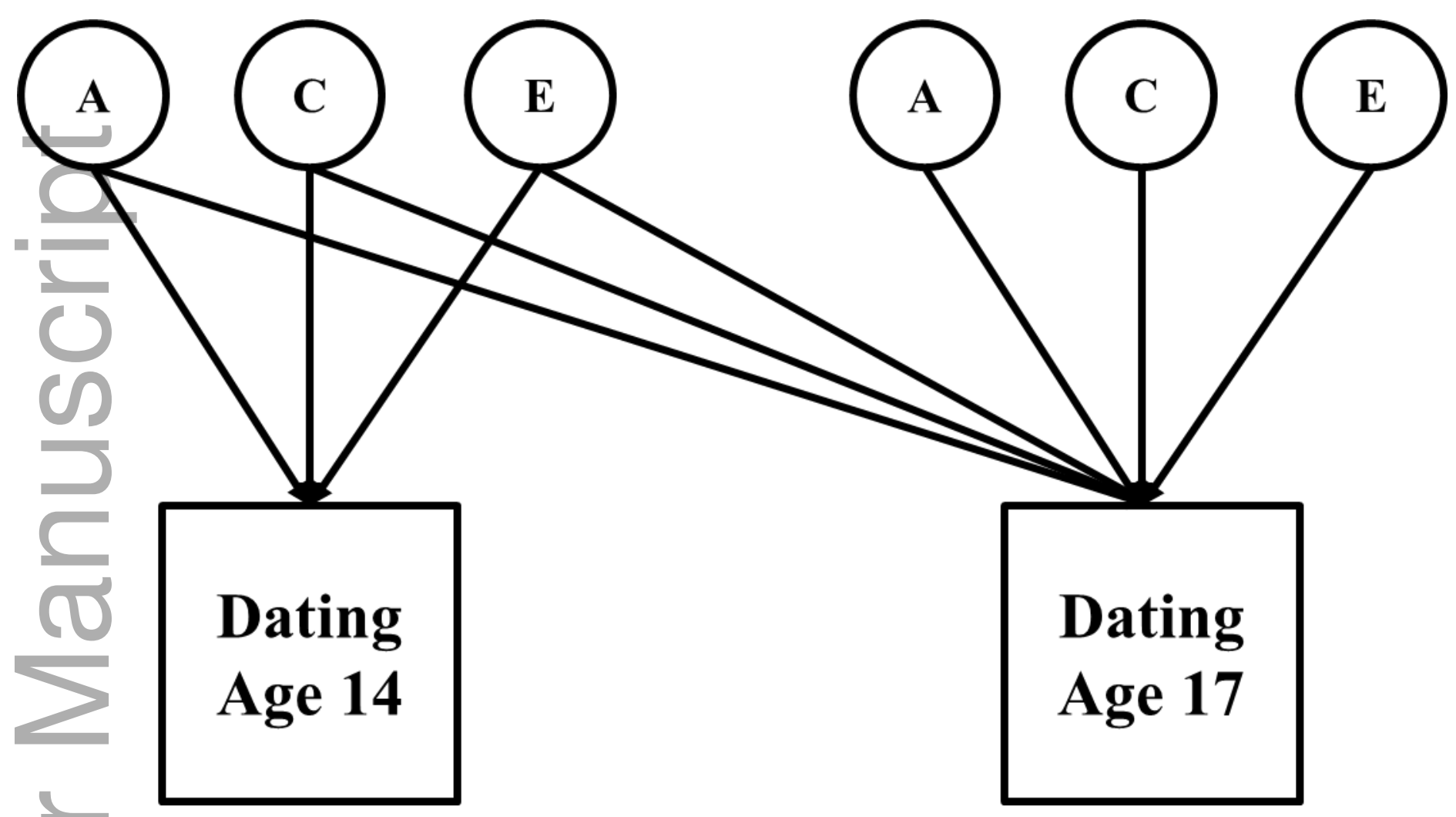

Figure 2. Bivariate ACE models (Cholesky Decomposition). $\mathrm{A}=$ additive genetic variance; $\mathrm{C}=$ shared environmental variance; $\mathrm{E}=$ nonshared environmental variance. Twin 2 model not pictured. Two equivalent models were specified, one for twin 1 and one for twin 2 , and covariances were added between the twin 1 and $2 \mathrm{~A}$ and $\mathrm{C}$ variance components. The covariance between the $\mathrm{A}$ components was fixed to 
either 1.0 (MZ twins) or 0.5 (DZ twins), and the covariance between the $\mathrm{C}$ components was fixed to 1.0 (MZ and DZ twins). Paths from the age 14 ACE components to the age 17 behavior capture the overlap between age 14 and age 17 ACE influences. The ACE components at age 17 capture ACE influences that are specific to age 17, and not shared with age 14 .

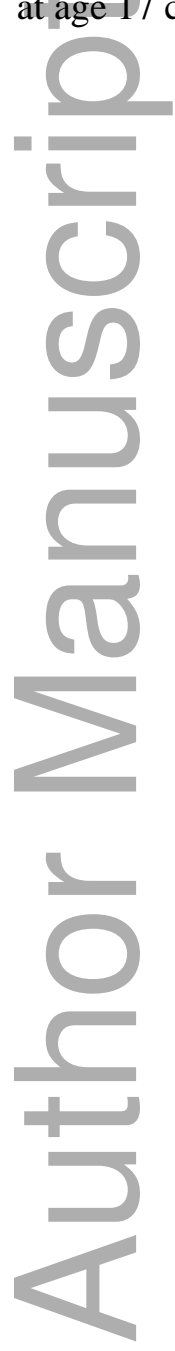

This article is protected by copyright. All rights reserved 

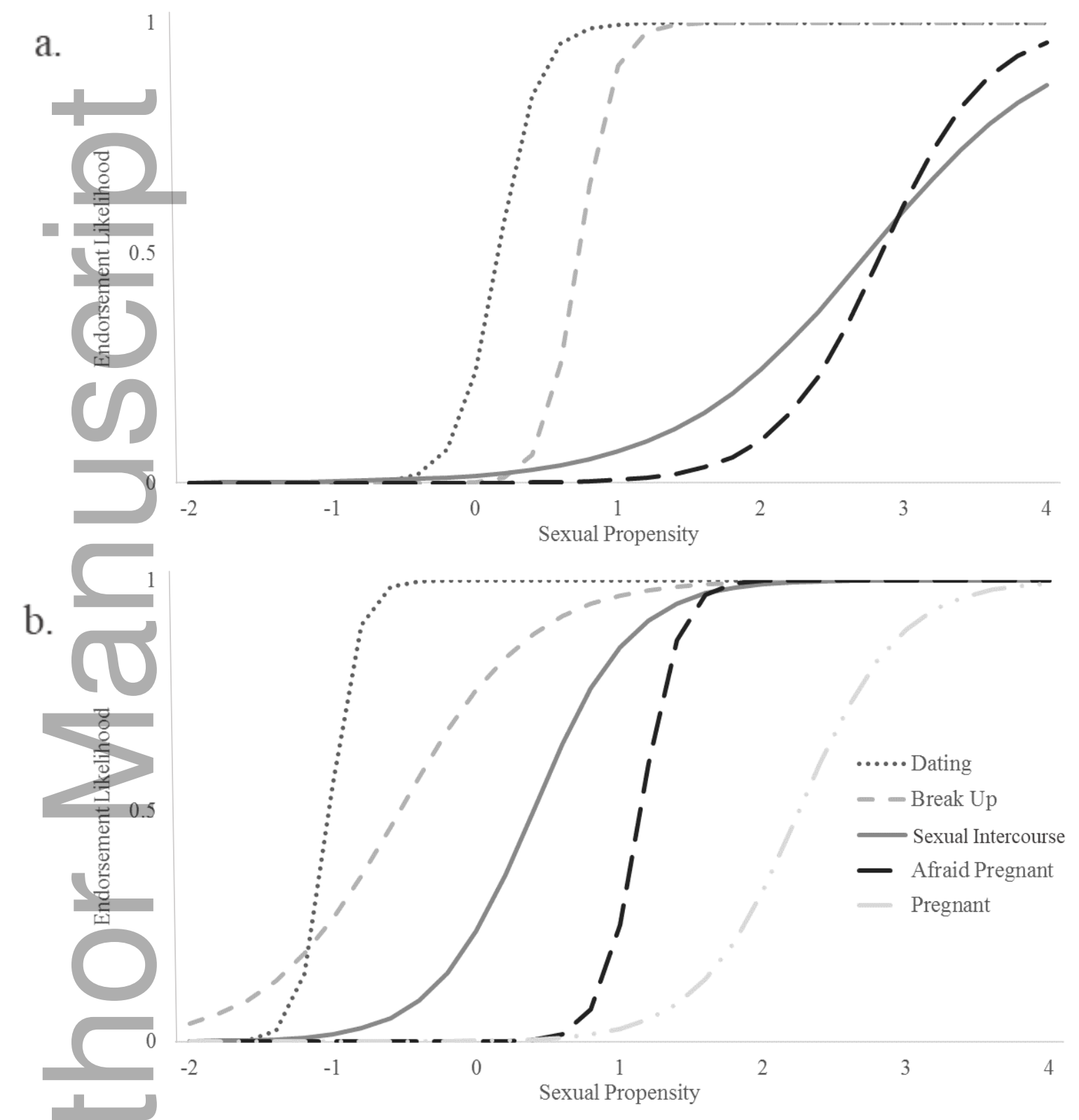

This article is protected by copyright. All rights reserved 
Figure 3. Item Characteristic Curves for different behaviors at age 14 and 17. Age 14 presented in panel a, age 17 presented in panel $\mathrm{b}$. Each number on the $\mathrm{X}$ axis represents the number of standard deviations removed from the mean (i.e., 0).

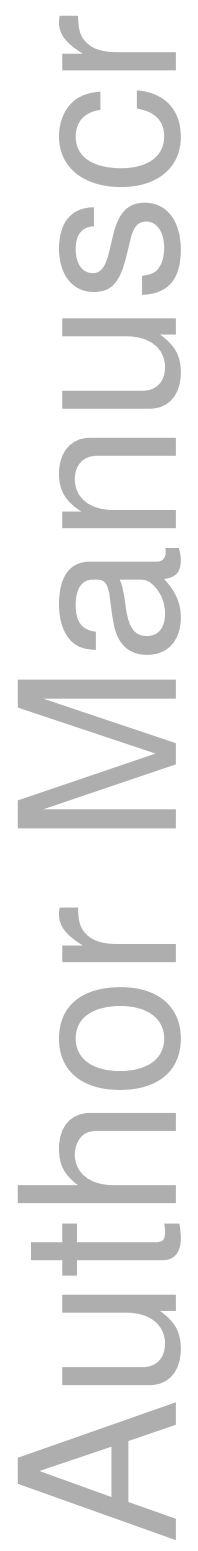

